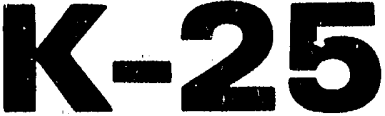

\section{OAK RIDGE K-25 SITE}

MARTIN MARIETIA
Effluent Testing for the Oak Ridge Toxic Substances Control Act Mixed Waste Incinerator Emissions Tests of January 16 and 18, 1991
J. T. Shor

W. D. Bostick

A. C. Coroneos

D. H. Bunch

L. V. Gibson

D. P. Hoffmann

J. L. Shoemaker 


\section{DISCLAIMER}

This report was prepared as an account of work sponsored by an agency of the United States Government. Neither the United States Government nor any agency thereof, nor any of their employees, makes any warranty, express or implied, or assumes any legal liability or responsibiiity for the accuracy, completeness, or usefulness of any information, apparatus, product, or process disclosed, or represents that its use would not infringe privately owned rights. Reference herein to any specific commercial product, process, or service by trade name, trademark, manufacturer, or otherwise does not necessarily constitute or imply its endorsement, recommendation, or favoring by the United States Government or any agency thereof. The views and opinions of authors expressed herein do not necessarily state or reflect those of the United States Government or any agency thereof. 


\title{
EFFLUENT TESTING FOR THE OAK RIDGE TOXIC SUBSTANCES CONTROL ACT MIXED WASTE INCINERATOR EMISSIONS TESTS OF JANUARY 16 AND 18, 1991
}

\author{
J. T. Shor
}

Chemical Technology Division

Oak Ridge National Laboratory

$$
\text { and }
$$

W. D. Bostick

A. C. Coroneos

D. H. Bunch

L. V. Gibson

D. P. Hoffmann

J. L. Shoemaker

Technical Division, K-25 Site

Date Published - February 1992

Prepared by the

OAK RIDGE K-25 SITE

Oak Ridge, Tennessee 37831

managed by

MARTIN MARIETTA ENERGY SYSTEMS, INC.

for the

U.S. DEPARTMENT OF ENERGY

under contract DE-AC05-84OR21400

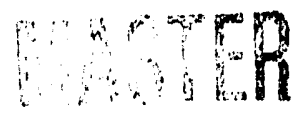




\section{CONTENTS}

Page

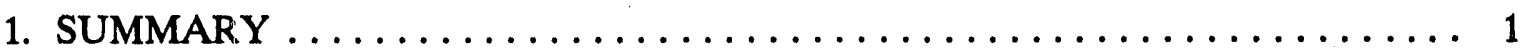

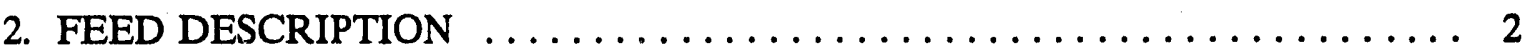

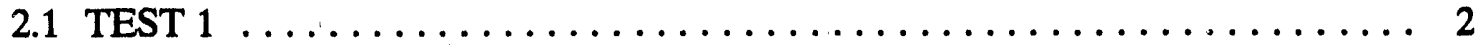

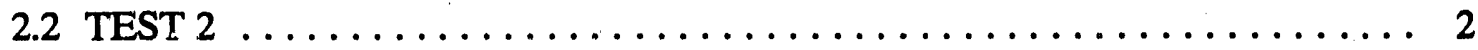

2.3 INCINERATOR OPERATING CONDITIONS $\ldots \ldots \ldots \ldots \ldots \ldots \ldots \ldots 2$

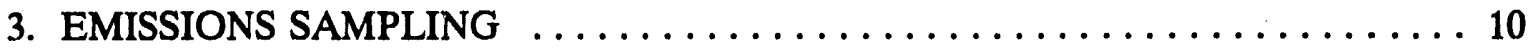

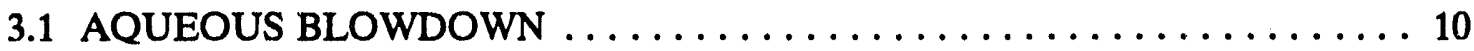

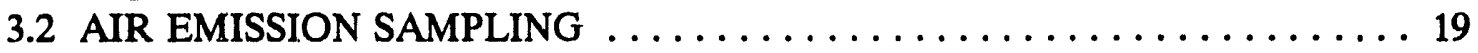

4. TREATMENT OF THE TSCA AQUEOUS EFFLUENT

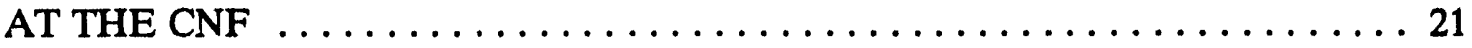

5. EXAMINATION OF ASH WATER AND ASH MATERIAL . . . . . . . . 29

6. NOTES ON SAMPLE PREPARATION AND ANALYSIS TECHNIQUES $\ldots . .32$

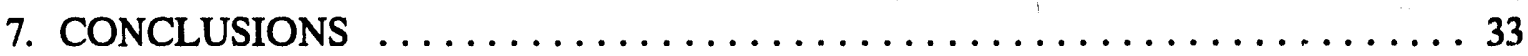

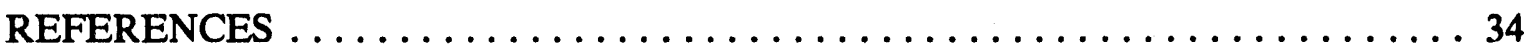

Appendix A: MICROCHARACTERIZATION OF TOXIC SUBSTANCES CONTROL ACT MIXED WASTE INCINERATOR EFFLUENT PARTICULATES 


\section{FIGURES}

Page

1. Sampling points (IWS $=$ ionizing wet scrubber $) \ldots \ldots \ldots \ldots \ldots$

2. Extrapolated particle size distribution for quench (QBD) and ionizing wet scrubber (IWS) blowdown, January 16, 1991, emission test ........................... 17

3. Extrapolated particle size distribution for quench (QBD) and ionizing wet scrubber (IWS) blowdown, January 18, 1991,

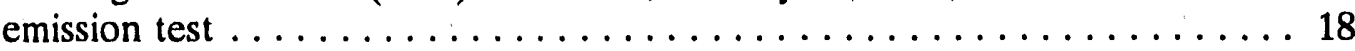

A.1 EDS spectrum for quench blowdown particulates $\ldots \ldots \ldots \ldots \ldots \ldots \ldots$

A.2 EDS spectrum for ionizing wet scrubber particulates $\ldots \ldots \ldots \ldots \ldots \ldots . \ldots 40$

A.3 EDS spectrum for stack emission particulates $\ldots \ldots \ldots \ldots \ldots \ldots \ldots \ldots$

A.4 Particle diameter data for quenciı blowdown solids:

(a) log-normal data plot and (b) computed distribution $\ldots \ldots \ldots \ldots \ldots$

A.5 Particle diameter data for stack emission solids and ionizing wet scrubber solids: (a) stack emission solids log-normal data plot and (b) ionizing wet scrubber solids computed distribution

A.6 Particle diameter data for ionizing wet scrubber solids and stack emission solids: (a) ionizing wet scrubber solids log-normal data plot and (b) stack emission computed distribution . . . . . . . . . 45

A.7(a) Micrograph of stack particulates at $1000 \mathrm{X} \ldots \ldots \ldots \ldots \ldots$

A.7(b) Micrograph of stack particulates at $2000 \mathrm{X} \ldots \ldots \ldots \ldots \ldots$

A.8(a) Micrograph of quench particulates at $1000 \mathrm{X} \ldots \ldots \ldots \ldots \ldots$

A.8(b) Micrograph of quench particulates at $2000 \mathrm{X} \ldots \ldots \ldots \ldots \ldots$

A.9(a) Micrograph of IWS particulates at $1000 \mathrm{X} \ldots \ldots \ldots \ldots \ldots \ldots$

A.9(b) Micrograph of IWS particulates at $2000 \mathrm{X} \ldots \ldots \ldots \ldots \ldots \ldots$ 


\section{TABLES}

1. Results of analyses of TSCA feed sample for Tank 307A,

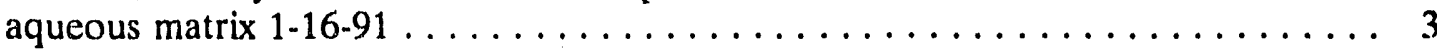

2. Results of analyses of TSCA feed sample for Task 306A,

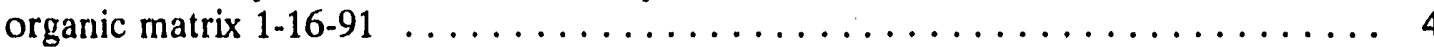

3. Results of analyses of TSCA feed sample for Task 305A,

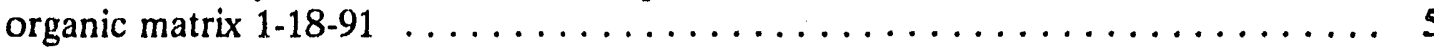

4. Results of analyses of TSCA feed sample (in parts per million)

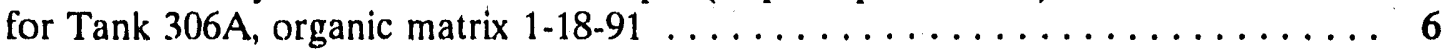

5. January 16,1991 , air test process conditions $\ldots \ldots \ldots \ldots \ldots \ldots \ldots \ldots \ldots$

6. January 18,1991 , air test process conditions $\ldots \ldots \ldots \ldots \ldots \ldots \ldots \ldots$

7. Results of analyses of TSCA waters for January 16, 1991, run for Tank 306A, organic matrix $1-18-91 \ldots \ldots \ldots \ldots \ldots \ldots \ldots$

8. Results of analyses of TSCA waters for January 18, 1991,

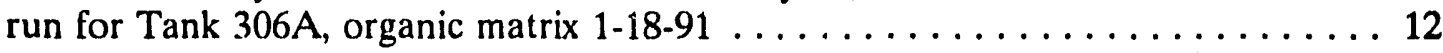

9. Partition of constituents into quench water blowdown $\ldots \ldots \ldots \ldots \ldots \ldots$

10. Particle size analysis (1-15-91 emissions test, backscattering laser mi roscope $) \ldots \ldots \ldots \ldots \ldots \ldots \ldots \ldots$

11. Particle size analysis (1-18-91 emissions test,

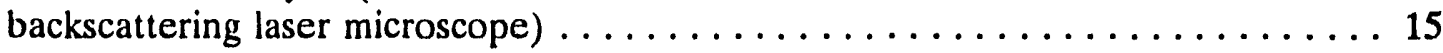

12. January 18, 1991, emissions test, Microtrac

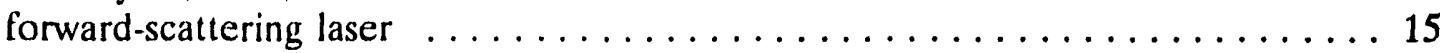

13. Forward-scattering Microtrac from unrelated,

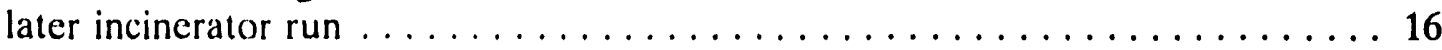

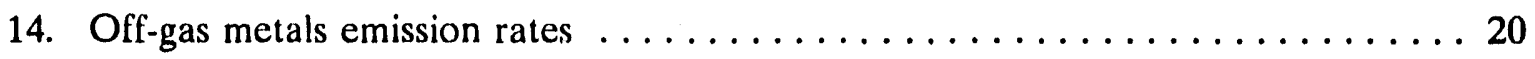

15. Results of analyses of TSCA waters treated at the CNF-batch 1 , January 17, 1991 
16. Results of analyses of TSCA waters-batch 2 , January $17,1991 \ldots \ldots \ldots$

17. Results of analyses of TSCA waters-batch 1 , January $19,1991 \ldots \ldots \ldots$

18. Results of analyses of TSCA waters-batch 2 , January $19,1991 \ldots \ldots \ldots$

19. Results of analyses of TSCA waters-batch 3 , January $19,1991 \ldots \ldots \ldots$

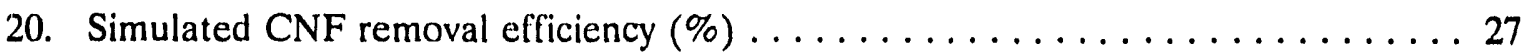

21. CNF samples after treatment, filtered $\ldots \ldots \ldots \ldots \ldots \ldots \ldots \ldots \ldots \ldots$

22. Results of analyses of TSCA waters $-1-16-91$ run $\ldots \ldots \ldots \ldots \ldots \ldots \ldots$

23. Results of analyses of TSCA waters-1-18-91 run $\ldots \ldots \ldots \ldots \ldots \ldots \ldots$

A.1. EDS analysis for TSCA effluent particulates $\ldots \ldots \ldots \ldots \ldots \ldots \ldots$

A.2. Particle size data for TSCA effluent particulates $\ldots \ldots \ldots \ldots \ldots \ldots \ldots \ldots$

A.3 EDS results for CNF-filtered material $\ldots \ldots \ldots \ldots \ldots \ldots \ldots \ldots \ldots$ 


\title{
EFFLUENT TESTING FOR THE OAK RIDGE TOXIC SUBSTANCES CONTROL ACT (TSCA) INCINERATOR EMISSIONS TESTS OF JANUARY 16 AND 18, 1991
}

\author{
J. T. Shor \\ W. D. Bostick \\ A. C. Coroneos \\ D. H. Bunch \\ L. V. Gibson \\ D. P. Hoffmann \\ J. L. Shoemaker
}

\section{SUMMARY}

On January 16 and 18, 1991, special emissions tests were conducted at the Oak Ridge K-25 Site Toxic Substances Control Act (TSCA) Incinerator. Both tests were approximately $6 \mathrm{~h}$ long and were performed at TSCA temperatures $\left[1200^{\circ} \mathrm{C}\right.$, secondary combustion chamber (SCC)]. Liquid feed and effluent samples were collected every $30 \mathrm{~min}$. A filter was used to collect particles from stack gases to study morphology and composition during the first test. Isokinetic air samples were also taken during the second test. Metals emissions from the second test were evaluated using the Environmental Protection Agency (EPA) Method 5 sampling train. The aqueous waste was collected and fed in batches to the Central Neutralization Facility (CNF), where it was treated by iron coprecipitation and polymer flocculation and data were collected.

In the first test (1-16-91), the aqueous and organic wastes were fed directly to the kiln or primary combustion chamber (PCC). In the second test (1-18-91), the remaining organic waste from the first test was fed into the SCC, and other organic waste was fed into the PCC. One objective of the two tests was to determine if feeding the same organic waste into the two combustion chambers made a difference in the partitioning of uranium and other metals. No evaluation of radionuclides other than uranium was made.

The partition coefficient of uranium to the quench water was 0.3 on January 16 ar $\rfloor 0.35$ on January 18; so directing Tank 306A to the feed to the primary vs the secondary combustion chamber appears to have made little difference. The partition coefficient of uranium to the stack on January 18 was 0.0039 . 


\section{FEED DESCRIPTION}

\subsection{TEST 1}

The aqueous waste in Test 1 (1-16-91) from Tank 307A was labeled contaminated flush water. This was water that was used to clean the incinerator contamination zone. It contained about 1440 ppm of polychlorinated biphenyl (PCB) liquids and had little heating value. The organic waste in Test 1 (and 2), from Tank 306A, was thought (but not confirmed) to be from a collection of drums stored in Bldg. K-726 at the K-25 Site and contained $670 \mathrm{ppm}$ of PCB liquids and $\approx 100-200 \mathrm{ppm}$ uranium. Its heating value was about $18,000 \mathrm{Btu} / \mathrm{lb}$. Based on a statistical analysis and triplicate sampling, it was found or determined to contain $5 \mathrm{ppm}$ mercury upper bound maximum, at the $90 / 95$ confidence interval. The detailed metal analyses of the two wastes are given in Tables 1 and 2, which feature data taken from samples during the burning of the waste (labelled on-line) and samples from storage tanks before (in some cases, well before) the incineration (labelled prenun). All partition coefficients are based on on-line feed sample data.

The sample preparation technique was different for most prerun and on-line metal analyses. The organic on-line samples were prepared for inductively coupled plasma (ICP) atomic emission spectroscopy using an apparatus known as a High-Pressure Asher (HPA). The HPA is generally more effective in digesting organic samples than its predecessor, the Parr bomb, which was used to prepare all prerun ICP analyses. Organics containing uranium were prepared in all cases using a Parr bomb. On-line and prerun analyses are, in general, quite different for several reasons. The on-line sample preparation of Tank 307A was performed using HPA even though the waste feed was largely aqueous. This could indicate a sample inhomogeneity (i.e., the sample was largely organic, though the tank was mostly aqueous), a mistake in preparation, or a mislabelled sample. For the other organic samples, the use of the Parr bomb and the HPA would be expected to yield different results. Sample heterogeneity is another problem; most samples contain varying amounts of particulates, and a representative sample from a tank is hard to obtain without thorough agitation. Crosscontamination can also occur in tank blending operations from the time of the prerun sampling to the on-line sampling. Such discrepancies were also observed in the August 1990 air test.

\subsection{TEST 2}

In Test 2 (1-18-91), the organic feed from Tank 306A was directed into the SCC instead of the PCC. The PCC feed, Tank 305A, was a PCB waste oil containing 13,000 ppm PCBs from the K-1425 Tank Farm originating from Y-12. Its heating value was about 19,000 Btu/lb. Detailed metal analysis data are shown in Tables 3 and 4 . A schematic of the feed locations and the sample points for both tests is shown in Fig. 1.

\subsection{INCINERATOR OPERATING CONDITIONS}

The waste streams were fed into the K-1435 TSCA Incinerator from approximately 1:30 to 7:30 p.m. on January 16 and 18, 1991. Incinerator operating parameters are summarized in Tables 5 and 6 . The comparatively low values of the dry oxygen concentration in Table 5 is believed to be because of a lack of accurate instrument calibration. The incinerator was operated above TSCA temperatures $\left(\mathrm{PCC}\right.$ at $1000^{\circ} \mathrm{C}, \mathrm{SCC}$ at $1200^{\circ} \mathrm{C}$ ) during both tests. 
3

Table 1. Results of analyses of TSCA feed sample for Tank 307A, aqueous matrix 1-16-91

\begin{tabular}{|c|c|c|c|}
\hline Metal & Units & $\begin{array}{c}910126-112 \\
\text { On-line }{ }^{a, b}\end{array}$ & $\begin{array}{c}891006- \\
166 \\
\text { Prerun }^{a}\end{array}$ \\
\hline Aluminum & $\mu \mathrm{g} / \mathrm{g}$ & 14 & 11 \\
\hline Antimony & $\mu \mathrm{g} / \mathrm{g}$ & $<7.9$ & 4.8 \\
\hline Arsenic & $\mu \mathrm{g} / \mathrm{g}$ & $<7.9$ & 0.98 \\
\hline Barium & $\mu \mathrm{g} / \mathrm{g}$ & 0.78 & 0.84 \\
\hline Beryllium & $\mu \mathrm{g} / \mathrm{g}$ & 0.12 & 0.075 \\
\hline Cadmium & $\mu \mathrm{g} / \mathrm{g}$ & 3.1 & 0.029 \\
\hline Calcium & $\mu \mathrm{g} / \mathrm{g}$ & 9200 & 9100 \\
\hline Chloride & $\mu \mathrm{g} / \mathrm{g}$ & & 13000 \\
\hline Chromium & $\mu \mathrm{g} / \mathrm{g}$ & 9.5 & 0.18 \\
\hline Copper & $\mu \mathrm{g} / \mathrm{g}$ & $<0.63$ & 0.91 \\
\hline Iron & $\mu \mathrm{g} / \mathrm{g}$ & 910 & 190 \\
\hline Lead & $\mu \mathrm{g} / \mathrm{g}$ & $<7.9$ & $27 / 1.4^{c}$ \\
\hline Lithium & $\mu \mathrm{g} / \mathrm{g}$ & 3.5 & 4.1 \\
\hline Magnesium & $\mu \mathrm{g} / \mathrm{g}$ & 20 & 19.8 \\
\hline Manganese & $\mu \mathrm{g} / \mathrm{g}$ & 23 & 6.6 \\
\hline Mercury, cold vapor AA & $\mu \mathrm{g} / \mathrm{g}$ & $<0.5$ & 0.48 \\
\hline Nickel & $\mu \mathrm{g} / \mathrm{g}$ & 1.8 & 1.07 \\
\hline Phosphorus & $\mu \mathrm{g} / \mathrm{g}$ & 88 & 70 \\
\hline Potassium & $\mu g / g$ & 450 & 280 \\
\hline Selenium & $\mu \mathrm{g} / \mathrm{g}$ & $<7.9$ & 0.005 \\
\hline Silicon & $\mu \mathrm{g} / \mathrm{g}$ & 250 & \\
\hline Silver & $\mu \mathrm{g} / \mathrm{g}$ & $<0.94$ & $0.06 \mathrm{U}$ \\
\hline Sodium & $\mu \mathrm{g} / \mathrm{g}$ & 210 & 237 \\
\hline Thorium & $\mu \mathrm{g} / \mathrm{g}$ & $<31$ & $2.0 \mathrm{U}$ \\
\hline Titanium & $\mu \mathrm{g} / \mathrm{g}$ & $<0.47$ & 0.27 \\
\hline Uranium fluorometric & $\mu \mathrm{g} / \mathrm{g}$ & $<1^{b}$ & 151 \\
\hline${ }^{235} \mathrm{U}$ (isotopic) & wt \% & & 0.64 \\
\hline Zinc & $\mu \mathrm{g} / \mathrm{g}$ & 7.1 & 12 \\
\hline
\end{tabular}

${ }^{a} U$ and $<$ indicate that elements were not detected at the limits of instrument sensitivity under the given conditions.

'Sample appeared to be organic, though the tank was predominantly aqueous; therefore, it was possibly not representative.

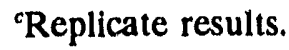


Table 2. Results of analyses of TSCA feed sample for Tank 306A, organic matrix 1-16-91

\begin{tabular}{|c|c|c|c|}
\hline Metal & Units & $\begin{array}{c}910126-112 \\
\text { On-Line }^{a}\end{array}$ & $\begin{array}{c}\text { 891006-166 } \\
\text { Prerun }^{a}\end{array}$ \\
\hline Aluminum & $\mu \mathrm{g} / \mathrm{g}$ & 23 & 230 \\
\hline Antimony & $\mu \mathrm{g} / \mathrm{g}$ & $<5$ & $<5.9$ \\
\hline Arsenic & $\mu \mathrm{g} / \mathrm{g}$ & $<5$ & 0.5 \\
\hline Barium & $\mu g / g$ & 4.7 & 16 \\
\hline Beryllium & $\mu \mathrm{g} / \mathrm{g}$ & $<0.030$ & 0.030 \\
\hline Cadmium & $\mu \mathrm{g} / \mathrm{g}$ & $0.30 \mathrm{U}$ & 1.1 \\
\hline Calcium & $\mu \mathrm{g} / \mathrm{g}$ & 230 & \\
\hline Chloride & $\mu \mathrm{g} / \mathrm{g}$ & & 4700 \\
\hline Chromium & $\mu \mathrm{g} / \mathrm{g}$ & 2.6 & 17 \\
\hline Copper & $\mu g / g$ & 2.4 & 31 \\
\hline Iron & $\mu \mathrm{g} / \mathrm{g}$ & 630 & 3200 \\
\hline Lead & $\mu \mathrm{g} / \mathrm{g}$ & 33 & 180 \\
\hline Lithium & $\mu g / g$ & 0.44 & 0.58 \\
\hline Magnesium & $\mu \mathrm{g} / \mathrm{g}$ & 20 & 73 \\
\hline Manganese & $\mu \mathrm{g} / \mathrm{g}$ & 14 & 27 \\
\hline Mercury & $\mu \mathrm{g} / \mathrm{g}$ & $<0.5$ & 2.06 \\
\hline Nickel & $\mu \mathrm{g} / \mathrm{g}$ & 3.1 & 32 \\
\hline Phosphorus & $\mu g / g$ & 560 & 820 \\
\hline Potassium & $\mu g / g$ & 250 & \\
\hline Selenium & $\mu \mathrm{g} / \mathrm{g}$ & $<7.9$ & 0.5 \\
\hline Silicon & $\mu \mathrm{g} / \mathrm{g}$ & 250 & \\
\hline Silver & $\mu \mathrm{g} / \mathrm{g}$ & $0.6 \mathrm{U}$ & $0.71 \mathrm{U}$ \\
\hline Sodium & $\mu \mathrm{g} / \mathrm{g}$ & 160 & 470 \\
\hline Thorium & $\mu \mathrm{g} / \mathrm{g}$ & $<31$ & \\
\hline Titanium & $\mu g / g$ & 6.9 & 25 \\
\hline Uranium & $\mu g / g$ & 216 & 544 \\
\hline${ }^{235} \mathrm{U}$ (Isotopic) & wt \% & & 0.71 \\
\hline Zinc & $\mu \mathrm{g} / \mathrm{g}$ & 41 & 420 \\
\hline
\end{tabular}

${ }^{a} U$ and < indicate that elements were not detected at the limits of instrument sensitivity under the given conditions. 
Table 3. Results of analyses of TSCA feed sample for Tank 305A, organic matrix 1-18-91

\begin{tabular}{|c|c|c|c|}
\hline Metal & Units & $\begin{array}{c}910126-112 \\
\text { On-line }^{a}\end{array}$ & $\begin{array}{c}891006-166 \\
\text { Prerun }^{a, b}\end{array}$ \\
\hline Aluminum & $\mu \mathrm{g} / \mathrm{g}$ & 14 & 14 \\
\hline Antimony & $\mu \mathrm{g} / \mathrm{g}$ & $<8.1$ & $5.0 \mathrm{U}$ \\
\hline Arsenic & $\mu \mathrm{g} / \mathrm{g}$ & $<8.1$ & $0.5 \mathrm{U}$ \\
\hline Barium & $\mu \mathrm{g} / \mathrm{g}$ & 3.1 & 2.7 \\
\hline Beryllium & $\mu \mathrm{g} / \mathrm{g}$ & 0.12 & 0.03 \\
\hline Cadmium & $\mu \mathrm{g} / \mathrm{g}$ & $<0.49$ & $0.3 \mathrm{U}$ \\
\hline Calcium & $\mu \mathrm{g} / \mathrm{g}$ & 123 & \\
\hline Chloride & $\mu \mathrm{g} / \mathrm{g}$ & & 13000 \\
\hline Chromium & $\mu g / g$ & 6.0 & $17 / 115^{c}$ \\
\hline Copper & $\mu \mathrm{g} / \mathrm{g}$ & $<0.65$ & 7.7 \\
\hline Iron & $\mu g / g$ & 350 & 150 \\
\hline Lead & $\mu g / g$ & 28 & 4.8 \\
\hline Lithium & $\mu \mathrm{g} / \mathrm{g}$ & $<0.65$ & 7.7 \\
\hline Magnesium & $\mu g / g$ & 14 & 14 \\
\hline Mangatiese & $\mu \mathrm{g} / \mathrm{g}$ & 9.3 & 2.3 \\
\hline Mercury, cold vapor AA & $\mu \mathrm{g} / \mathrm{g}$ & $<0.5$ & 1.1 \\
\hline Nickel & $\mu g / g$ & 4.0 & $8.0 / 131^{c}$ \\
\hline Phosphorus & $\mu \mathrm{g} / \mathrm{g}$ & 720 & 590 \\
\hline Pot.ussium & $\mu \mathrm{g} / \mathrm{g}$ & 700 & \\
\hline Selenium & $\mu g / g$ & $<8.1$ & \\
\hline Silicon & $\mu g / g$ & 910 & \\
\hline Silver & $\mu \mathrm{g} / \mathrm{g}$ & $<0.97$ & $0.59 \mathrm{U}$ \\
\hline Sodium & $\mu \mathrm{g} / \mathrm{g}$ & 140 & 17 \\
\hline Thorium & $\mu \mathrm{g} / \mathrm{g}$ & $<32$ & \\
\hline Titanium & $\mu \mathrm{g} / \mathrm{g}$ & 0.55 & 1.1 \\
\hline Uranium fluorometric & $\mu g / g$ & 100 & 84 \\
\hline${ }^{233} \mathrm{U}$ (isotopic) & wt \% & & 0.73 \\
\hline Zinc & $\mu \mathrm{g} / \mathrm{g}$ & 31 & 14 \\
\hline
\end{tabular}

${ }^{a} \mathrm{U}$ and $<$ indicate that elements were not detected at the limits of instrument sensitivity under the given conditions.

${ }^{b}$ Blend of several tanks; first nurnber indicates preponderant sample analysis; second number is provided where variations exist.

'Replicate results, showing large variation. 
Table 4. Results of analyses of TSCA feed sample (in parts per million) for Tank 306A, organic matrix 1-18-91

\begin{tabular}{|c|c|c|}
\hline Metal & $\begin{array}{c}910126-112 \\
\text { On-line }^{a}\end{array}$ & $\begin{array}{c}891006-166 \\
\text { Prerun }^{a}\end{array}$ \\
\hline Aluminum & 10 & 230 \\
\hline Antimony & $<8.0$ & $<5.9$ \\
\hline Arsenic & $<8.0$ & 0.5 \\
\hline Barium & 1.7 & 16 \\
\hline Beryllium & 0.085 & 0.030 \\
\hline Cadmium & $<0.48$ & 1.1 \\
\hline Calcium & 57 & \\
\hline Chloride & & 4700 \\
\hline Chromium & 4.9 & 17 \\
\hline Copper & 3.9 & 31 \\
\hline Iron & 150 & 3200 \\
\hline Lead & $<8.0$ & 180 \\
\hline Lithium & $<0.64$ & 0.58 \\
\hline Magnesium & 7.2 & 73 \\
\hline Manganese & 2.1 & 27 \\
\hline Mercury, cold vapor AA & $<0.5$ & 2.06 \\
\hline Nickel & 1.9 & 32 \\
\hline Phosphorus & 570 & 820 \\
\hline Potassium & 590 & \\
\hline Selenium & $<8.0$ & $<0.5$ \\
\hline Silicon & 790 & \\
\hline Silver & $<0.96$ & $0.71 \mathrm{U}$ \\
\hline Sodium & 25 & 470 \\
\hline Thorium & $<32$ & \\
\hline Titanium & $<0.48$ & 25 \\
\hline Uranium fluorometric & 88 & 544 \\
\hline Zinc & 12 & 420 \\
\hline
\end{tabular}

${ }^{a} \mathrm{U}$ and $<$ indicate that elements were not deterted at the limits of instrument sensitivity under the given conditions. 


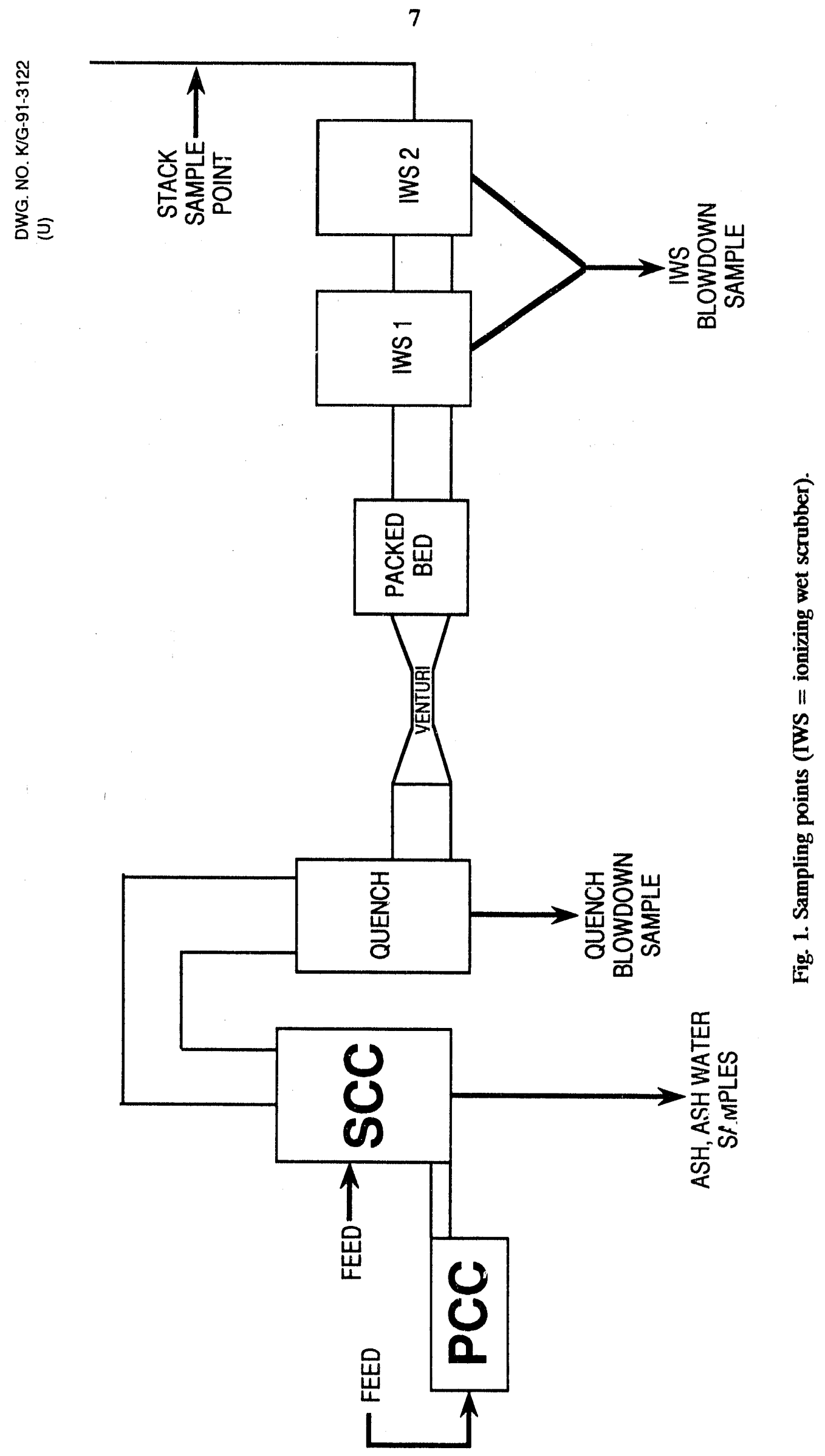


Table 5. January 16, 1991, air test process conditions

\begin{tabular}{|c|c|c|c|c|}
\hline Parameter (all wastes were fed as liquids) & Mean & Minimum & Maximum & $\begin{array}{l}\text { Standard } \\
\text { deviation }\end{array}$ \\
\hline PCC, kiln, $\mathrm{T},{ }^{\circ} \mathrm{F}$ & 1831 & 1820 & 1839 & 5.7 \\
\hline $\mathrm{SCC}, \mathrm{T},{ }^{\circ} \mathrm{F}$ & 2228 & 2229 & 2235 & 8.8 \\
\hline PCC, organic feed, lb/h, Tank 306A & 241.4 & 210 & 291 & 19.8 \\
\hline PCC, aqueous feed, $\mathrm{lb} / \mathrm{h}$, Tank 307A & 73.1 & 0 & 104 & 28.2 \\
\hline SCC, organic feed, lb/h & 0 & & & \\
\hline Methane feed to PCC, scfh & 10,980 & 10,590 & 11,420 & 281 \\
\hline Auxiliary combustion air to PCC, scfm & 1178 & 1166 & 1185 & 5.6 \\
\hline Methane feed to SCC, scfh & 13.610 & 13,090 & 14,720 & 426 \\
\hline Auxiliary combustion air to SCC, scfm & 1783 & 1696 & 1947 & 66 \\
\hline PCC waste combustion, air $\mathrm{scfm}^{b}$ & 965 & 1068 & 838 & 67 \\
\hline $\mathrm{SCC}$ waste combustion, air $\mathrm{scfm}^{c}$ & 1766 & 1660 & 1910 & 61 \\
\hline Kiln face plate pressure, w.c., in. & -0.81 & -1.1 & -0.7 & 0.09 \\
\hline Quench, $\mathrm{T},{ }^{\circ} \mathrm{F}$ & 180 & 179 & 181 & 1.0 \\
\hline Quench recycle flow, gal/min & 12 & 111 & 127 & 5.1 \\
\hline Quench blowdown, gal/min & 10.7 & 7.3 & 15.6 & 2.49 \\
\hline Venturi pressure drop, w.c., in. & 8.56 & 8.41 & 8.67 & 0.065 \\
\hline Venturi recycle flow, gal/min & 148 & 143 & 153 & 2.65 \\
\hline Packed bed recycle, gal/min & 151 & 150 & 151 & 0.08 \\
\hline Packed bed $\mathrm{pH}$ & 6.94 & 6.3 & 7.4 & 0.32 \\
\hline IWS, \#1, recycle flow, gal/min & 520 & 515 & 524 & 3.14 \\
\hline IWS, \#2, recycle flow, gal/min & 581 & $336^{d}$ & & \\
\hline IWS, \#1, voltage, $\mathrm{kV}$ & 21.8 & 18.5 & 25.2 & 1.86 \\
\hline IWS, \#2, voltage, $\mathrm{kV}$ & 22.5 & 0 & 25.4 & 5.0 \\
\hline IWS blowdown gal/min & 8.46 & 0 & 56.4 & 18.4 \\
\hline Total APC blowdown, gal/min & 19.7 & 7.3 & 64.2 & 17 \\
\hline Combustion gas velocity, $\mathrm{ft} / \mathrm{s}$ & 21.0 & 19.8 & 21.9 & 0.56 \\
\hline Stack gas CO concentration, ppm, dry basis & 2.5 & 0 & 4 & 0.93 \\
\hline Stack gas $\mathrm{O}_{2}$ concentration, $\%$, dry basis & 8.8 & 8.4 & 9.0 & 0.2 \\
\hline Stack gas $\mathrm{CO}_{2}$ concentration, $\mathrm{ppm}$, dry basis & 7.03 & 6.88 & 7.33 & 0.11 \\
\hline
\end{tabular}

${ }^{a}$ Number of measurements was 24 ; performed each $10 \mathrm{~min} . \mathrm{SCC}=$ secondary combustion chamber; $\mathrm{PCC}=$ primary combustion chamber; IWS $=$ ionizing wet scrubber.

'2800 scfm output, maximum.

¿4162 scfm output, maximum.

${ }^{d} 336$ value is suspiciously low.

eAir pollution control system. 
Table 6. January 18, 1991, air test process conditions

\begin{tabular}{|c|c|c|c|c|}
\hline Parameter (all wastes were fed as liquids) & Mean & Minimum & Maximum & $\begin{array}{l}\text { Standard } \\
\text { deviation }\end{array}$ \\
\hline PCC, kiln, $\mathrm{T},{ }^{\circ} \mathrm{F}$ & 1854 & 1838 & 1903 & 11.9 \\
\hline $\mathrm{SCC}, \mathrm{T},{ }^{\circ} \mathrm{F}$ & 2230 & 2221 & 2241 & 4.3 \\
\hline PCC, organic feed, lb/h, Tank 306A & 547 & 450 & 578 & 20.3 \\
\hline PCC, aqueous feed, $1 \mathrm{~b} / \mathrm{h}$, Tank 307A & 0 & 0 & 0 & 0 \\
\hline $\mathrm{SCC}$, organic feed, lb/h & 247 & 0 & 468 & 120 \\
\hline Methane feed to PCC, sch & 1936 & 1620 & 7010 & 1056 \\
\hline Auxiliary combustion air to PCC, scfm & 319 & 262 & 1188 & 180 \\
\hline Methane feed to SCC, scfh & 10,110 & 9320 & 11,230 & 844 \\
\hline Auxiliary combustion air to SCC, scfm & 1318 & 924 & 1474 & 112 \\
\hline PCC waste combustion, air scfm & 1263 & 912 & 1322 & 74.5 \\
\hline SCC waste combustion, air scfm & 769 & 383 & 970 & 225 \\
\hline PCC kiln face plate pressure, w.c., in. & -0.75 & -1.0 & -0.4 & 0.13 \\
\hline Quench, water temperature, ${ }^{\circ} \mathrm{F}$ & 178 & 181 & 175 & 2.3 \\
\hline Quench recycle flow, gal/min & 120 & 115.7 & 126 & 2.7 \\
\hline Quench ble ddown, gal/min & 17.2 & 13.5 & 21.4 & 2.36 \\
\hline Venturi pressure drop, w.c., in. & 8.50 & 8.22 & 8.62 & 0.12 \\
\hline Venturi recycle flow, gal/min & 143 & 134 & 150 & 9.4 \\
\hline Packed bed recycle, gal/min & 146 & 136 & 149 & 8.8 \\
\hline Packed bed pH & 6.7 & 6.1 & 7.6 & 0.52 \\
\hline IWS, \#1, recycle flow, gal/min & 519 & 513 & 524 & 3.1 \\
\hline IWS, \#2, recycle flow, gal/min & 586 & 570 & 601 & 7.4 \\
\hline IWS, \#1, voltage, $\mathrm{kV}$ & 21.9 & 0 & 23.3 & 1.2 \\
\hline IWS, \#2, voltage, $\mathrm{kV}$ & 22.6 & 20.1 & 23.4 & 0.96 \\
\hline IWS blowdown, gal/min & 36.7 & 0 & 68.9 & 16.3 \\
\hline Tótal APC blowdown, gal/min & 53.9 & 26 & 75.9 & 15.2 \\
\hline Combustion gas velocity, $\mathrm{ft} / \mathrm{s}$ & 18.2 & 17.2 & 19.6 & 0.54 \\
\hline Stack gas CO concentraiion, ppm, dry basis & 3.2 & 1 & 7 & 2.6 \\
\hline Stack gas $\mathrm{O}_{2}$ concentration, $\%$, dry basis & 10.0 & 8.6 & 11.5 & 1.1 \\
\hline Stack gas $\mathrm{CO}_{2}$ concentration, $\mathrm{ppm}$, dry basis & 7.0 & 5.38 & 8.54 & 1.3 \\
\hline
\end{tabular}

${ }^{a}$ Number of measurements was 27 ; performed each $15 \mathrm{~min} . \mathrm{SCC}=$ secondary combustion chamber; PCC = primary combustion chamber; IWS = ionizing wet scrubber.

${ }^{b}$ Air pollution control system. 


\section{EMISSIONS SAMPLING}

\subsection{AQUEOUS BLOWDOWN}

Although the K-1435 TSCA Incinerator has five scrubbing stages, purge streams (known as blowdown) are taken from only two points: (1) the quench chamber and (2) a composite of the two ionizing wet scrubber (IWS) effluents. The blowdown rate depends on the $\mathrm{pH}$ and conductivity of the solution and is monitored continuously. The blowdown rates are therefore variable. In the case of the combined IWS streams, these rates are extremely variable and are not considered here for the purposes of calculating partition coefficients. As can be seen from Tables 5 and 6, the IWS blowdown dropped to 0 on occasion, and the average flow rate data are not very meaningful. The blowdown is collected in a surge tank $(603 \mathrm{~A})$ and a purge basin (602B) $(40,000$ and 30,000 gal, respectively). Samples of these tanks were taken to determine the PCB content. The solutions were sent in batches to the CNF if $<1$ part per billion (ppb) PCBs was found. Otherwise, the solution was fed to activated carbon beds to remove the residual $\mathrm{PCBs}$ and then sent to the CNF.

As in previous emissions tests, samples were taken every $30 \mathrm{~min}$, composited, and then submitted to the K-25 Site Analytical Chemistry Laboratory for analysis under chain-ofcustody. The analytical resulis of the IWS and quench slurry samples are shown in Tables 7 and 8 for the January 16 and 18 runs, respectively. One difficulty in obtaining representative samples was the presence of solid particles in the blowdown slurries. Although attempts were made to mix the slurries at every point at which the samples were decanted, inevitably, there were losses. The larger particles settled rapidly, and the analytical results generally underestimate their constituent concentration.

Tables 7 and 8 reveal no observable trend toward enrichment of volatile metals in the IWS vs the quench blowdown slurries. Fine particles might themselves be enriched in volatile metals and the trend unapparent, however. Elements such as calcium, iron, and aluminum were reduced in concentration in the IWS blowdown. This may mean that the larger particulate matter was enriched in these elements.

A partition coefficient can be defined operationally as the fraction of total constituent fed to the incinerator that appears in a given effluent stream. In Table 9 are shown the partition coefficients of selected metals to the quench blowdown based on the on-line feed analyses. Metals partition coefficients are shown only as a function of the overall blowdown concentration, since analyses of the filtered solids and filtrate were not separately performed as in the August 1990 emissions test. These numbers represent the fraction of feed metal that was recovered in the quench slurry of solids and liquid. The " $C$ " indicates that the results were comparable (within reasonable error bounds) in the January 1991 and the August 1990 experiments. The " $L$ " indicates values that were lower in the August 1990 tests. Partition coefficients greater than 1 may indicate an admixture of the element-in the case of sodium, as sodium hydroxide scrubbing solution. In other cases, the causes are not obvious but may be from corrosion, from impurities in the $\mathrm{NaOH}$, from errors in the analysis, and from detritus remaining from previous incinerator runs. Although in the 1-18-91 and 1-16-91 experiments 34.7 and $9.7 \mathrm{~g} / \mathrm{h}$ of uranium, respectively, were fed into the incinerator, the uranium partition coefficients to the blowdown (and the soluble uranium concentrations) are similar but very different from the values reported in the August 1990 test. 
11

Table 7. Results of analyses of TSCA waters for January 16, 1991, run for Tank 306A, organic matrix 1-18-91

\begin{tabular}{|c|c|c|}
\hline Metal & $\begin{array}{c}\text { TS-011691-IWS } \\
910126-118 \\
(\mathrm{mg} / \mathrm{L})\end{array}$ & $\begin{array}{c}\text { TS-011691-QCH } \\
910126-119 \\
(\mathrm{mg} / \mathrm{L})\end{array}$ \\
\hline Aluminum & 0.55 & 1.6 \\
\hline Antimony & $<0.050$ & $<0.050$ \\
\hline Barium & 0.14 & 0.31 \\
\hline Beryllium & 0.0032 & 0.0014 \\
\hline Boron & 0.062 & 0.23 \\
\hline Cadmium & 0.0046 & $<0.0030$ \\
\hline Calcium & 84 & 220 \\
\hline Chromium & 0.12 & 0.15 \\
\hline Cobalt & $<0.050$ & 0.0083 \\
\hline Copper & 0.28 & 0.17 \\
\hline Iron & 15 & 25 \\
\hline Lead & 1.3 & 1.1 \\
\hline Lithium & 0.16 & 0.094 \\
\hline Magnesium & 15 & 43 \\
\hline Manganese & 0.26 & 0.33 \\
\hline Mercury & $<0.0002$ & 0.00021 \\
\hline Molybdenum & 0.019 & 0.027 \\
\hline Nickel & 0.10 & 0.11 \\
\hline Niobium & $<0.0070$ & 0.012 \\
\hline Phosphorus & 10 & 16 \\
\hline Potassium & 9.8 & 11 \\
\hline Silicon & 16 & 14 \\
\hline Silver & 0.0075 & 0.0077 \\
\hline Sodium & 210 & 950 \\
\hline Strontium & 0.68 & 0.80 \\
\hline Thorium & $<0.20$ & $<0.20$ \\
\hline Titanium & 0.13 & 0.62 \\
\hline Uranium & 0.65 & 2.90 \\
\hline Vanadium & 0.0072 & 0.0070 \\
\hline Zinc & 1.4 & 1.0 \\
\hline Zirconium & $<0.0050$ & 0.0088 \\
\hline
\end{tabular}


12

Table 8. Results of analyses of TSCA waters for January 18, 1991, run for Tank 306A, organic matrix 1-18-91

\begin{tabular}{|c|c|c|}
\hline Metal & $\begin{array}{c}\text { TS-011891-IWS } \\
910126-121 \\
(\mathrm{mg} / \mathrm{L})\end{array}$ & $\begin{array}{c}\text { TS-011891-QCH } \\
910126-122 \\
(\mathrm{mg} / \mathrm{L})\end{array}$ \\
\hline Aluminum & 0.58 & 2.0 \\
\hline Antimony & $<0.050$ & $<0.050$ \\
\hline Barium & 0.12 & 0.29 \\
\hline Beryllium & 0.0015 & 0.00080 \\
\hline Boron & 0.042 & 0.22 \\
\hline Cadmium & 0.0060 & $<0.0030$ \\
\hline Calcium & 33 & 110 \\
\hline Chromium & 0.14 & 0.14 \\
\hline Cobalt & 0.0058 & 0.013 \\
\hline Copper & 0.25 & 0.19 \\
\hline Iron & 11 & 22 \\
\hline Lead & 1.4 & 0.71 \\
\hline Lithium & 0.14 & 0.084 \\
\hline Magnesium & 11 & 29 \\
\hline Manganese & 0.20 & 0.28 \\
\hline Mercury & $<0.0002$ & $<0.0002$ \\
\hline Molybdenum & 0.076 & 0.067 \\
\hline Nickel & 0.13 & 0.016 \\
\hline Niobium & 0.016 & 0.033 \\
\hline Phosphorus & 14 & 15 \\
\hline Potassium & 7.1 & 9.9 \\
\hline Silicon & 17 & 11. \\
\hline Silver & $<0.0060$ & 0.0089 \\
\hline Sodium & 140 & 2000 \\
\hline Strontium & 0.14 & 0.32 \\
\hline Thorium & $<0.20$ & $<0.20$ \\
\hline Titanium & 0.067 & 0.65 \\
\hline Uranium fluorometric & 1.19 & 3.16 \\
\hline Vanadium & 0.0093 & 0.0076 \\
\hline Zinc & 1.3 & 1.00 \\
\hline Zirconium & $<0.0050$ & 0.011 \\
\hline
\end{tabular}


13

Table 9. Partition of constituents into quench water blowdown"

\begin{tabular}{|c|c|c|c|}
\hline \multirow[b]{2}{*}{ Element } & \multicolumn{3}{|c|}{ Partition coefficients ${ }^{b}$} \\
\hline & January 16 & January 18 & August 1990 \\
\hline Aluminum & 1.3 & 1.7 & $2.9 \mathrm{C}$ \\
\hline \multicolumn{4}{|l|}{ Arsenic } \\
\hline Barium & 1.39 & 1.18 & $3.44 \mathrm{C}$ \\
\hline Beryllium & 0.468 & 0.079 & 2.76 \\
\hline Cadmium & 0.0537 & 0.0667 & 0.068 \\
\hline Chromium & 0.607 & 0.267 & $0.025 \mathrm{~L}$ \\
\hline Copper & 1.45 & 1.24 & $0.94 \mathrm{C}$ \\
\hline Iron & 0.6 & 0.827 & $0.75 \mathrm{C}$ \\
\hline Mercury & $<0.00715$ & $<0.00433$ & \\
\hline Manganese & 0.349 & 0.255 & $0.217 \mathrm{C}$ \\
\hline Sodium & 237 & 207 & \\
\hline Nickel & 0.670 & 0.518 & $0.0145 \mathrm{~L}$ \\
\hline Antimony & 0.15 & 0.0071 & \\
\hline Lead & 0.089 & 0.353 & $0.522 \mathrm{C}$ \\
\hline Uranium & 0.297 & 0.355 & $0.0145 \mathrm{~L}$ \\
\hline Zinc & 0.514 & 0.432 & $1.16 \mathrm{C}$ \\
\hline $\begin{array}{l}\quad \text { a" }<" \text { in } \\
\text { limits of de } \\
C=\text { compt } \\
\text { August } 199 \\
\text { bDefine } \\
\text { feed). }\end{array}$ & $\begin{array}{l}\text { tates that the } \\
\text { tability and } \\
\text { ole to Janua } \\
\text { est. } \\
\text { s (mass } / \mathrm{h} \text { in }\end{array}$ & $\begin{array}{l}\text { are based } \\
\text { nsequently } \\
1 \text { tests; } L= \\
\text { lown stream }\end{array}$ & $\begin{array}{l}\text { lata at the } \\
\text { iable. } \\
\text { r than during } \\
\text { ass } / \mathrm{h} \text { in on-line }\end{array}$ \\
\hline
\end{tabular}


For the first time in these emissions tests, data were gathered on the particle size distribution of the solids present in the quench and IWS blowdown samples. The data were collected using two techniques: (1) a Leeds and Northrup Microtrac forward laser scattering particle size analyzer and (2) a newer device, Lasentec, Labtec 100, backscattering laser microscope. The former instrument requires a minimum concentration of 1 to $5 \mathrm{~g}$ of solids, while the latter can handle lower concentrations accurately and, in fact, is limited to low concentrations because of its scanning mode of operation. The light-scattering techniques are relatively insensitive to very small particles, with a detection limit of approximately $2 \mu \mathrm{m}$ for the forward-scatter instrument and approximately $0.7 \mu \mathrm{m}$ for the backscatter device.

Data of the particle histograms (assuming that the particles are spherical) from the IWS and quench water from both runs using the Lasentec microscope are presented in Tables 10 and 11. Also presented in Table 12 are results from the Microtrac for the quench and ash from the 1-18-91 run. The Microtrac quench data were unreliable because of an inadequate concentration of particles (according to the instrument operator). A very uneven distribution was obtained, and the high value of the mean particle diameter, $83 \mu \mathrm{m}$, was not reasonable. The ash results, being of higher concentration, are believed to be good. A second quench water sample from another subsequent (unrelated) incinerator run was taken and analyzed using the Microtrac. A larger and higher concentration was available, and the results from the quench were quite close to the earlier results from the Labtec microscope from the 1-16/1-18 emissions tests. This indicates the Microtrac's ability to yield good data given proper concentration samples. However, a similar sample of the IWS scrub water taken from this subsequent run again proved too low in concentration to measure accurately. Data are shown in Table 13.

Table 10. Particle size analysis (1-16-91 emissions test, backscattering laser microscope)

\begin{tabular}{lccccc}
\hline \multirow{2}{*}{$\begin{array}{l}\text { Particle size } \\
\text { range }(\mu \mathrm{m})\end{array}$} & \multicolumn{2}{c}{ Quench water } & & \multicolumn{2}{c}{ IWS water } \\
\cline { 2 - 3 } \cline { 5 - 6 } & $\%$ & Cum. \% & & $\%$ & Cum. \% \\
\hline 2 & 20 & 20 & & 21 & 21 \\
$2-4$ & 30 & 50 & & 53 & 74 \\
$4-8$ & 31 & 81 & & 23 & 97 \\
$8-16$ & 18 & 99 & & 3 & 100 \\
$16-31$ & 2 & 101 & & &
\end{tabular}

$31-63$

Lognormal

particle size

distribution

Median $(\mu \mathrm{m})$

$\begin{array}{lll}\text { Spread factor } & 2.2 & 1.6\end{array}$ 
Table 11. Particle size analysis (1-18-91 emissions test, backscattering laser microscope)

\begin{tabular}{|c|c|c|c|c|}
\hline \multirow{2}{*}{$\begin{array}{l}\text { Particle size } \\
\text { range }(\mu \mathrm{m})\end{array}$} & \multicolumn{2}{|c|}{ Quench water } & \multicolumn{2}{|c|}{ IWS water } \\
\hline & $\%$ & Cum. \% & $\%$ & Cum. \% \\
\hline$\leq 2$ & 19 & 19 & 33 & 33 \\
\hline $2-4$ & 29 & 48 & 41 & 74 \\
\hline $4-8$ & 36 & 84 & 22 & 96 \\
\hline $8-16$ & 13 & 97 & 4 & 100 \\
\hline $16-31$ & 2 & 99 & & \\
\hline \multicolumn{5}{|l|}{$\begin{array}{l}\text { Lognormal } \\
\text { particle size } \\
\text { distribution }\end{array}$} \\
\hline Median ( $\mu \mathrm{m})$ & & 3.4 & 2.3 & \\
\hline Spread factor & & 2.1 & 1.9 & \\
\hline
\end{tabular}

Table 12. January 18, 1991, emissions test, Microtrac forward-scattering laser

\begin{tabular}{lccccc}
\hline & \multicolumn{2}{c}{ Ash supply } & & \multicolumn{2}{c}{ Quench } \\
\cline { 2 - 3 } \cline { 5 - 6 } Particle size $(\mu \mathrm{m})$ & $\%$ & Cum. \% & & $\%$ & Cum. \% \\
\hline 3176 & 14 & 14 & & 16.5 & 16.5 \\
$38-125$ & 10.5 & 24.5 & & 16.5 & 33 \\
$62-88$ & 15 & 39.5 & & 14 & 47 \\
$44-62$ & 14.9 & 54.4 & & 10.5 & 57.5 \\
$31-44$ & 7.2 & 61.6 & & 7.6 & 65.1 \\
$22-31$ & 9.4 & 71 & & 8.2 & 73.3 \\
$16-22$ & 5.4 & 76.4 & & 8.4 & 81.7 \\
$11-16$ & 2.0 & 78.4 & & 5.8 & 87.5 \\
$7.8-11$ & 8.9 & 87.3 & & 2.6 & 90.1 \\
$5.5-7.8$ & 3.3 & 90.6 & & 4.0 & 94.1 \\
$3.9-5.5$ & 2.1 & 92.7 & & 3.9 & 98 \\
$2.8-3.9$ & 3.7 & 96.4 & & 2.4 & 100 \\
$<2.8$ & 2.8 & 99.2 & 3.8 & \\
Median $=$ & & 48 & $\mu \mathrm{m}$ & & \multicolumn{2}{c}{$=83$} \\
\hline
\end{tabular}


Table 13. Forward-scattering Microtrac from unrelated, later incinerator run

\begin{tabular}{lccccc}
\hline & \multicolumn{2}{c}{ Quench 030991} & & \multicolumn{2}{c}{ IWS 030941 } \\
\cline { 2 - 3 } \cline { 5 - 6 } Particle diam $(\mu \mathrm{m})$ & $\%$ & Cum. \% & & $\%$ & Cum. \% \\
\hline 2.8 & 29.5 & 29.5 & 10 & 10 \\
3.9 & 17.3 & 46.8 & & 9.5 & 19.5 \\
5.5 & 15.3 & 62.1 & & 12.3 & 31.9 \\
7.8 & 5 & 67.1 & & 5.9 & 37.7 \\
11.0 & 5.8 & 72.9 & & 3.6 & 41.3 \\
16.0 & 11.3 & 83.9 & & 10.3 & 51.6 \\
22.0 & 5.5 & 89.4 & & 8.1 & 59.7 \\
31.0 & 1.0 & 90.4 & & 0.7 & 60.4 \\
44.0 & 0.9 & 91.3 & & 10.9 & 71.3 \\
62.0 & 0.9 & 92.2 & & 13.4 & 84.7 \\
88.0 & 4.9 & 97.1 & & 0.1 & 84.8 \\
125.0 & 2.8 & 99.9 & & 8.5 & 93.3 \\
176.0 & 0 & & 6.9 & 100 \\
& $\mathrm{dp}$ & $4.24 \mu \mathrm{m}^{\circ}$ & & $\mathrm{dp}=15.3 \mu \mathrm{m}^{a}$ \\
\hline
\end{tabular}

${ }^{a}$ Arithmetic mean.

The geometric mean or median $(\mathrm{Cg})$ particle sizes of 3.4 to $3.8 \mu \mathrm{m}$ in the quench water and 2.3 to $2.9 \mu \mathrm{m}$ in the IWS water from Tables 10 and 11 were fairly consistent with the limited particle size data from the August 1990 air test, ${ }^{1}$ which showed a range in particle size from

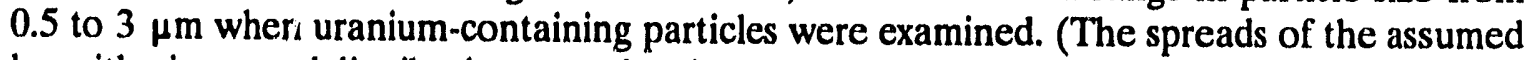
logarithmic nornal distributions are also shown.) Plots of the distributions extrapolated fron the available data are shown in Figs. 2 and 3 from the January 16 and 18 tests. The somewhat smaller size of the particles in the IWS vs the quench were expected since the IWS is the final stage of scrubbing before the stack. Although the concentrations of particles (i.e., suspended solids) were not accurately measured, it was clear that the IWS slurries were, in general, less concentrated. The fact that the concentrations of most trace metals were similar in both IWS and quench waters is worth noting. Beryllium, lithium, and lead were less concentrated in the IWS waters from both experiments. Evidently, little fine fractionation of trace metal occurs between the two scrubbers on the opposite ends of the air pollution control system; yet the quench blowdown is clearly more concentrated in undissolved solids. 


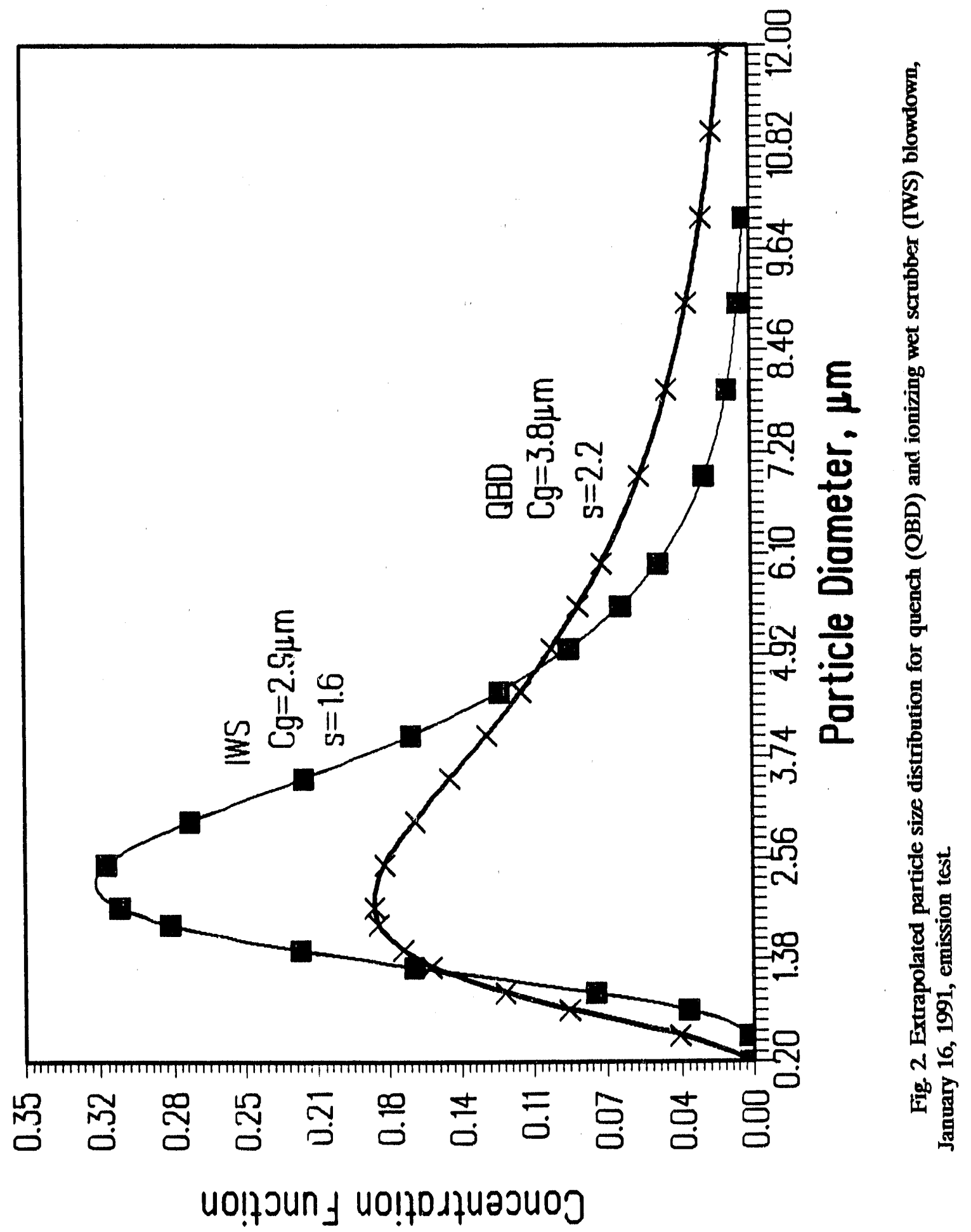




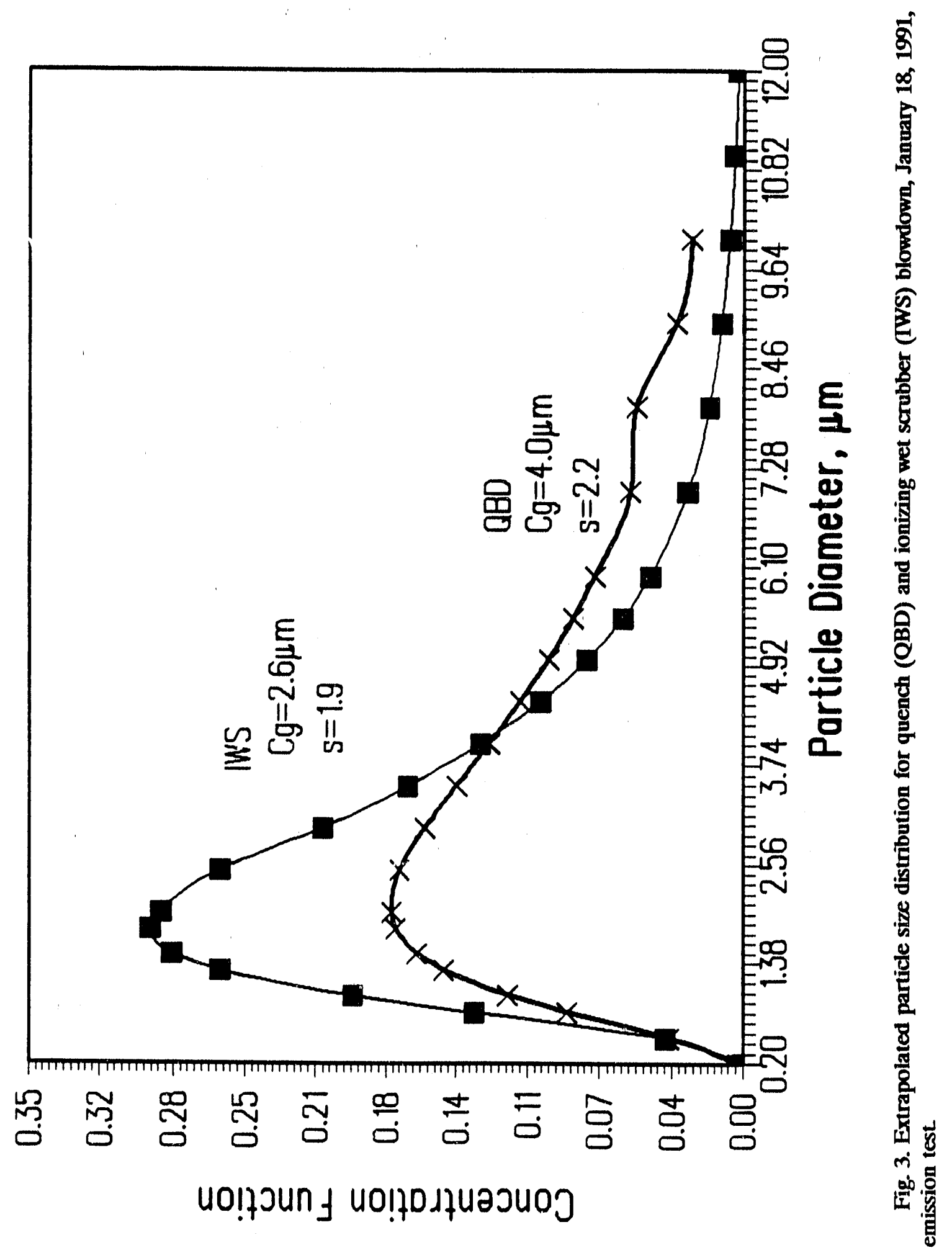


This may result from silicon-containing particulates that were not dissolving well during the sample digestion procedure. The results from the August 1990 emissions test were similar in overall character.

Light micrographs were made of the quench and IWS blowdown slurries, and they are shown in Figs. A.8 ( $a$ and b) and A.9 ( $a$ and b) of Appendix A. They demonstrate that the particle shapes were fairly regular, often round, and generally amenable to the laser microscope histogram analysis, which assumes spherical particles and is least effective with long, needle-shaped (prolate) particles. The square-like crystals are believed to be quartz, based on their behavior in polarized light. The round particles are reminiscent of coal fly ash, which fuses at high temperature to form spheres, the shape of lowest surface energy. Spheroidized silica particles have been found in coal-fired boilers of temperatures as low as $900^{\circ} \mathrm{C}^{2}$ These light micrographs were made because it was felt that the electron microscopy sample preparation might alter the morphology of the particles or result in particle aggregation. The micrographs confirm that the average particulate size is smaller in IWS blowdown and that the solids are less concentrated. The larger number of dark particles in this polarized light photograph suggests the presence of elements of higher atomic weight.

\subsection{AIR EMISSION SAMPLING}

During the first emissions test (January 16, 1991), a carbon-coated millipore filter was used to isokinetically capture stack gas particulates for examination under an electron microscope. A mask was used to limit the area of collection of the particle; however, in practice, it proved ineffective, and particles deposited over the entire filter area. The particles appeared to be a dull yellow color. More on this test will be reported in Appendix A.

During the second emissions test, an EPA Multiple Metals Sampling Train was used to sample isokinetically for a variety of metals in a highly standardized procedure. The results are shown in Table 14. The emission data rate of uranium is suspect because a major fraction of the total uranium collected was obtained anomalously from the last stage impinger of the sampling train. This anomaly may result from sample contamination because the uranium, if present, would be expected to be found in the first stages and in gradually diminishing amounts in the latter stages.

Arsenic appeared to have the greatest potential to partition significantly to the stack; the element and its oxides and chlorides are volatile. The vapor pressure of $\mathrm{As}_{2} \mathrm{O}_{3}$ is so great at the incinerator exit gas temperature that it is thermodynamically possible that all arsenic escaped as $\mathrm{As}_{2} \mathrm{O}_{3}$ vapor. ${ }^{3}$ The same is true of mercury, the next most significant metal partitioning to the stack. The concentration of arsenic measured in the off-gas was at the instrumental detection limits, however, and may be interpreted as maximum emissions. The emissions data for mercury may underestimate its true concentration because the sampling train was modified (for safety reasons) to remove the potassium permanganate solution normally used to absorb mercury.

The results potentially represent an overestimate of uranium to the stack because of the anomalous impinger data; yet the mass balance indicates that about $0.4 \%$ of the uranium fed to the incinerator escaped from the stack as compared with $2.9 \%$ in the August 1990 test. The absolute quantities and concentrations of uranium fed during this test were less than in 
Table 14. Off-gas metals emission rates ${ }^{a}$

\begin{tabular}{|c|c|c|c|c|}
\hline Element & $\begin{array}{l}\text { Feed rate } \\
(\mathrm{g} / \mathrm{h}) \\
8-27-90\end{array}$ & $\begin{array}{c}\text { Feed rate } \\
(\mathrm{g} / \mathrm{h}) \\
1-18-91 \\
\end{array}$ & $\begin{array}{c}\text { Emission rate } \\
(\mathrm{g} / \mathrm{h}) \\
1-18-91 \\
\end{array}$ & $\begin{array}{c}\text { Partition coefficient } \\
\text { basis on-line test } \\
(\%) \\
1-18-91\end{array}$ \\
\hline Arsenic ${ }^{c}$ & & $<2.9$ & $<2.29$ & $<79$ \\
\hline Barium $^{c}$ & 0.599 & 0.96 & 0.0795 & 8.3 \\
\hline Beryllium & 0.0343 & 0.039 & 0.000197 & 0.5 \\
\hline Cadmium $^{c}$ & 0.0482 & $<0.175$ & 0.00167 & $<0.9$ \\
\hline Chromium $^{c}$ & 48.8 & 2.04 & 0.135 & 6.6 \\
\hline Copper & 3.97 & 0.590 & 0.0565 & 9.6 \\
\hline Lead $^{c}$ & 11.5 & $<7.84$ & 0.224 & $<2.8$ \\
\hline Magnesium & & & 0.387 & \\
\hline Manganese & 10.8 & 4.28 & 0.043 & 1.0 \\
\hline Mercury ${ }^{c}$ & 0.08126 & $<0.18$ & $<0.051$ & $<28$ \\
\hline Nickel & 68.8 & 1.2 & 0.032 & 2.7 \\
\hline Phosphorus & 544 & 220 & 2.55 & 1.2 \\
\hline Selenium & & & $<2.30$ & \\
\hline Silver $^{c}$ & & 37.5 & 0.121 & 0.3 \\
\hline Thallium $^{c}$ & & & $<0.139$ & \\
\hline Uranium & 96 & 34.6 & 0.136 & 0.39 \\
\hline
\end{tabular}

August 1990. The incinerator air pollution control devices (APCD) may have operated more efficiently during the January 1991 test, at these lower concentrations. The refractory brick had also been replaced shortly before the January 1991 tests and would be expected to have little preexisting uranium contamination. 


\section{TREATMENT OF THE TSCA AQUEOUS EFFLUENT AT THE CNF}

The IWS and quench blowdown streams were collected in the TSCA surge tank and basin, as previously discussed, and sent to the CNF for final treatment before discharge to the environment. Five batch transfers were made from the two emissions test runs. The 1-16-91 emissions test generated two batches, and the 1-18-91 air test generated three. The first batch from the 1-18-91 test was cocontaminated with heel (waste from the K-1232 Chemical Recovery Facility) and other TSCA waters unrelated to the test. It consisted only of $40 \%$ blowdown water from the air test. Little contamination is believed to be present in the other batches, and this series probably provides the closest correlation yet available between the TSCA feed and the CNF-treated water discharged to J Basin, the final stage before it enters the water discharge. The batches are identified by date and number [e.g., batch $2(1 / 19 / 91)$ was the second batch treated on the 19th].

The metals analyses from each batch are shown in Tables 15 to 19. The suffix "BT" applies to the slurried samples as received and before any treatment. They were taken from a sampling valve on the bottom of Tank 240B of the CNF. The samples with the suffixes "ATP" and "ATF" were taken after the wastes had been treated with an iron sulfate compound (designed to precipitate and adsorb other metals and enhance the treatment efficiency) and/or a polymeric flocculant. For batches $1,2,3(1 / 19 / 91)$, samples were taken from the pipe to the sludge thickener at the CNF and contain only iron flocculant additive; batches 1 and 2 $(1 / 17 / 91)$ were taken at $\mathrm{J}$ Basin and should contain polymeric flocculant as well. There was a concern that at the $\mathrm{J}$ Basin the polymer may not be properly mixed with the waste water. The ATF samples were filtered using a $0.45-\mathrm{mu}$ millipore filter to simulate the action of the treatment plant sludge thickener. The ATP slurry samples were acidified to a $\mathrm{pH}$ less than 2 to preserve metals in solution. Evidently, in batches 1 and $2(1 / 17 / 91)$ the samples were filtered and then pickled; in batches 1,2 , and 3 (1/19/91), they were "pickled" but never filtered and contain metals such as aluminum, lead, iron, and others that are usually removed by filtration.

In general, the BT and ATP sample analyses should be similar to the composite blowdown samples. Nominally, $15 \mathrm{ppm}$ of iron were added during treatment, although perhaps because of poor mixing only 10-12 ppm were found in the sample. The removal efficiency for a selected group of metals is shown in Table 20. Although the efficiency was variable in the five batches, no metals except manganese were even close to either the EPA primary or secondary drinking water standards. The concentrations of a number of metals of regulatory concern, alongside reference drinking water standards, are shown in Table 21. It is not clear why the uranium removal efficiency appears lower during the January 19, 1991, treatment process as compared with the January 17, 1991, operations, or with the August 27, 1990, test. A comparison of the data in Table 20 for the $1 / 16 / 91$ burn (treated at CNF on 1/17/91) suggests that insufficient iron reagent was added in batch 2 and that removal efficiency for most constituents of regulatory interest may have been impaired, relative to batch 1 . 
Table 15. Results of analyses of TSCA waters treated at the CNFbatch 1, January 17, 1991

\begin{tabular}{|c|c|c|c|}
\hline Element & $\begin{array}{l}910211-108 \\
\text { CNF-011791- } \\
\text { 1ATF (mg/L) }\end{array}$ & $\begin{array}{l}901211-107 \\
\text { CNF-011791- } \\
1 \text { ATP (mg/L) }\end{array}$ & $\begin{array}{c}910211-115 \\
\text { CNF-011791- } \\
\text { 1BT (mg/L) }\end{array}$ \\
\hline Aluminum & 0.044 & 0.084 & 1.6 \\
\hline Antimony & $<0.050$ & $<0.050$ & $<0.050$ \\
\hline Barium & 0.013 & 0.015 & 0.10 \\
\hline Beryllium & $<0.00030$ & $<0.00030$ & 0.0015 \\
\hline Boron & 0.068 & 0.060 & 0.058 \\
\hline Cadmium & $<0.0030$ & $<0.0030$ & $<0.030$ \\
\hline Calcium & 110 & 100 & 99 \\
\hline Chromium & $<0.010$ & 0.018 & 0.068 \\
\hline Cobalt & $<0.0050$ & $<0.0050$ & 0.0077 \\
\hline Copper & 0.0051 & 0.0049 & 0.14 \\
\hline Iron & 0.010 & 0.62 & 31 \\
\hline Lead & $<0.050$ & $<0.050$ & 0.17 \\
\hline Lithium & 0.041 & 0.041 & 0.051 \\
\hline Magnesium & 16 & 15 & 18 \\
\hline Manganese & 0.025 & 0.035 & 0.21 \\
\hline Mercury & $<0.002$ & $<0.0002$ & 0.00072 \\
\hline Molybdenum & 0.019 & 0.014 & $<0.010$ \\
\hline Nickel & 0.036 & 0.036 & 0.13 \\
\hline Niobium & $<0.0070$ & $<0.0070$ & $<0.0070$ \\
\hline Phosphorus & 1.2 & 1.2 & 4.9 \\
\hline Potassium & 4.4 & 4.2 & 5.7 \\
\hline Silicon & 6.1 & 5.7 & 8.4 \\
\hline Silver & 0.0060 & $<0.0060$ & $<0.0060$ \\
\hline Sodium & 120 & 120 & 170 \\
\hline Strontium & 0.29 & 0.29 & 0.33 \\
\hline Thorium & $<0.20$ & $<0.20$ & $<0.20$ \\
\hline Titanium & $<0.0030$ & 0.0032 & 0.084 \\
\hline Uranium & 0.18 & 0.18 & 0.96 \\
\hline Vanadium & $<0.0050$ & $<0.0050$ & 0.0085 \\
\hline Zinc & 0.0066 & 0.017 & 0.43 \\
\hline Zirconium & $<0.0050$ & $<0.0050$ & 0.0072 \\
\hline
\end{tabular}


23

Table 16. Results of analyses of TSCA waters-batch 2, January 17, 1991

\begin{tabular}{|c|c|c|c|}
\hline Element & $\begin{array}{l}\text { 910211-106 } \\
\text { CNF-011791- } \\
\text { 2ATF (mg/L) }\end{array}$ & $\begin{array}{l}901211-105 \\
\text { CNF-011791- } \\
\text { 2ATP (mg/L) }\end{array}$ & $\begin{array}{c}\text { 910211-117 } \\
\text { CNF-011791- } \\
\text { 2RT (mg/L) }\end{array}$ \\
\hline Aluminum & 0.030 & 0.097 & 0.29 \\
\hline Antimony & $<0.050$ & $<0.050$ & $<0.005$ \\
\hline Barium & 0.015 & 0.015 & 0.039 \\
\hline Beryllium & $<0.00030$ & $<0.00030$ & $<0.00030$ \\
\hline Boron & 0.065 & 0.082 & 0.068 \\
\hline Cadmium & $<0.0030$ & $<0.0030$ & $<0.0030$ \\
\hline Calcium & 120 & 110 & 98 \\
\hline Chromium & $<0.010$ & $<0.010$ & 0.033 \\
\hline Cobalt & $<0.0050$ & $<0.0050$ & $<0.0050$ \\
\hline Copper & 0.0058 & 0.0061 & 0.022 \\
\hline Iron & 0.014 & 0.55 & 2.3 \\
\hline Lead & $<0.050$ & $<0.050$ & $<0.050$ \\
\hline Lithium & 0.043 & 0.042 & 0.049 \\
\hline Magnesium & 16 & 15 & 17 \\
\hline Manganese & 0.026 & 0.035 & 0.063 \\
\hline Mercury & $<0.0008$ & $<0.0002$ & $<0.0002$ \\
\hline Molybdenum & $<0.010$ & $<0.010$ & $<0.010$ \\
\hline Nickel & 0.030 & 0.038 & 0.047 \\
\hline Niobium & $<0.0070$ & $<0.007$ & $<0.0070$ \\
\hline Phosphorus & 0.98 & 1.0 & 2.2 \\
\hline Potassium & 4.6 & 4.4 & 5.8 \\
\hline Silicon & 6.6 & 5.5 & 6.2 \\
\hline Silver & 0.0077 & $<0.0060$ & $<0.0060$ \\
\hline Sodium & 120 & 120 & 210 \\
\hline Strontium & 0.30 & 0.29 & 0.29 \\
\hline Thorium & $<0.20$ & $<0.20$ & $<0.20$ \\
\hline Titanium & $<0.0030$ & 0.0044 & 0.013 \\
\hline Uranium & 0.21 & 0.217 & 0.63 \\
\hline Vanadium & $<0.0050$ & $<0.0050$ & $<0.0050$ \\
\hline Zinc & 0.011 & 0.016 & 0.087 \\
\hline Zirconium & $<0.0050$ & $<0.0050$ & $<0.0050$ \\
\hline
\end{tabular}


24

Table 17. Results of analyses of TSCA waters - batch 1, January 19, 1991

\begin{tabular}{|c|c|c|c|}
\hline Element & $\begin{array}{c}910211-113 \\
\text { CNFM-011991- } \\
1 \mathrm{ATF}(\mathrm{mg} / \mathrm{L})\end{array}$ & $\begin{array}{l}910211-112 \\
\text { CNFM-01199. } \\
\text { 1ATP (mg/L) }\end{array}$ & $\begin{array}{c}\text { 910211-111 } \\
\text { CNFNi-01199. } \\
\text { 1BT (mg/L) }\end{array}$ \\
\hline Aluminum & 0.032 & 0.43 & 0.39 \\
\hline Antimony & $<0.050$ & $<0.050$ & $<0.050$ \\
\hline Barium & 0.0079 & 0.048 & 0.050 \\
\hline Beryllium & $<0.00030$ & 0.00031 & 0.00030 \\
\hline Boron & 0.078 & 0.092 & 0.088 \\
\hline Cadmium & $<0.0030$ & $<0.0030$ & $<0.0030$ \\
\hline Calcium & 62 & 67 & 68 \\
\hline Chromium & 0.016 & 0.053 & 0.073 \\
\hline Cobalt & $<0.0050$ & 0.0059 & $<0.0050$ \\
\hline Copper & 0.0094 & 0.20 & 0.047 \\
\hline Iron & 0.022 & 14 & 4.3 \\
\hline Lead & $<0.050$ & 0.24 & 0.17 \\
\hline Lithium & 0.051 & 0.050 & 0.058 \\
\hline Magnesium & 14 & 14 & 15 \\
\hline Manganese & 0.034 & 0.082 & 0.053 \\
\hline Mercury & $<0.0008$ & $<0.0002$ & $<0.0002$ \\
\hline Molybdenum & 0.022 & 0.034 & 0.031 \\
\hline Nickel & 0.025 & 0.046 & 0.072 \\
\hline Niobium & $<0.0070$ & $<0.0070$ & 0.0092 \\
\hline Phosphorus & 0.21 & 3.3 & 3.5 \\
\hline Potassium & 5.2 & 5.6 & 5.8 \\
\hline Silicon & 4.9 & 4.2 & 3.5 \\
\hline Silver & $<0.0060$ & $<0.0060$ & 0.0086 \\
\hline Sodium & 430 & 440 & 470 \\
\hline Strontium & 0.14 & 0.16 & 0.17 \\
\hline Thorium & $<0.20$ & $<0.2 .0$ & $<0.20$ \\
\hline Titanium & $<0.0030$ & 0.030 & $<0.030$ \\
\hline Uranium & 0.64 & 1.03 & 0.98 \\
\hline Vanadium & $<0.0050$ & $<0.0059$ & $<0.0050$ \\
\hline Zinc & 0.014 & 0.24 & 0.19 \\
\hline Zirconium & $<0.0050$ & $<0.0050$ & $<0.0050$ \\
\hline
\end{tabular}


Table 18. Results of analyses of TSCA waters-batch 2, January 19, 1991

\begin{tabular}{|c|c|c|c|}
\hline Element & $\begin{array}{l}\text { 910211-104 } \\
\text { CNF-011991- } \\
\text { 1ATF (mg/L) }\end{array}$ & $\begin{array}{l}910211-103 \\
\text { CNF-011991- } \\
\text { 1ATP (mg/L) }\end{array}$ & $\begin{array}{c}910211-114 \\
\text { CNF-011991- } \\
\text { 1BT (mg/L) }\end{array}$ \\
\hline Aluminum & 0.055 & 0.60 & 0.31 \\
\hline Antimony & $<0.050$ & 0.050 & $<0.050$ \\
\hline Barium & 0.0096 & 0.028 & 0.027 \\
\hline Beryllium & $<0.00030$ & $<0.00030$ & $<0.00030$ \\
\hline Boron & 0.089 & 0.072 & 0.079 \\
\hline Cadmium & 0.0086 & $<0.0030$ & 0.0052 \\
\hline Calcium & 120 & 120 & 52 \\
\hline Chromium & $<0.010$ & 0.037 & 0.039 \\
\hline Cobalt & $<0.0057$ & 0.0057 & $<0.0050$ \\
\hline Copper & 0.012 & 0.098 & 0.028 \\
\hline Iron & 0.011 & 13 & 2.8 \\
\hline Lead & $<0.050$ & 0.13 & 0.056 \\
\hline Lithium & 0.055 & 0.054 & 0.054 \\
\hline Magnesium & 14 & 13 & 14 \\
\hline Manganese & 0.045 & 0.093 & 0.028 \\
\hline Mercury & $<0.0008$ & $<0.0002$ & $<0.0002$ \\
\hline Molybdenum & 0.033 & 0.025 & 0.038 \\
\hline Nickel & 0.023 & 0.045 & 0.030 \\
\hline Niobium & $<0.0070$ & $<0.0070$ & $<0.0070$ \\
\hline Phosphorus & $<0.20$ & 2.2 & 2.4 \\
\hline Potassium & 5.9 & 5.4 & 5.7 \\
\hline Silicon & 5.3 & 5.0 & 5.4 \\
\hline Silver & $<0.0060$ & 0.0073 & $<0.0060$ \\
\hline Sodium & 480 & 450 & 470 \\
\hline Strontium & 0.16 & 0.17 & 0.14 \\
\hline Thorium & $<0.20$ & $<0.20$ & $<0.20$ \\
\hline Titanium & $<0.0030$ & 0.026 & 0.014 \\
\hline Uranium & 0.62 & 1.08 & 1.03 \\
\hline Vanadium & $<0.0050$ & 0.0051 & 0.0053 \\
\hline Zinc & 0.01012 & 0.12 & 0.079 \\
\hline Zirconium & $<0.0050$ & $<0.0050$ & $<0.0050$ \\
\hline
\end{tabular}


26

Table 19. Results of analyses of TSCA waters-batch 3, January 19, 1991

\begin{tabular}{|c|c|c|c|}
\hline Element & $\begin{array}{c}910211-109 \\
\text { CNF-011991- } \\
\text { 2ATF (mg/L) }\end{array}$ & $\begin{array}{l}910211-110 \\
\text { CNF.011991. } \\
\text { 2ATP (mg/L) }\end{array}$ & $\begin{array}{r}910211-116 \\
\text { CNF-011991. } \\
\text { 2BT (mg/L) }\end{array}$ \\
\hline Aluminum & 0.021 & 0.58 & 0.37 \\
\hline Antimony & $<0.050$ & $<0.050$ & $<0.050$ \\
\hline Barium & 0.0071 & 0.025 & 0.021 \\
\hline Beryllium & $<0.00030$ & $<0.00030$ & 0.00030 \\
\hline Boron & 0.073 & 0.078 & 0.070 \\
\hline Cadmium & $<0.0030$ & $<0.0030$ & $<0.030$ \\
\hline Calcium & 110 & 140 & 66 \\
\hline Chromium & 0.011 & 0.030 & 0.076 \\
\hline Cobalt & $<0.0050$ & 0.0081 & $<0.0050$ \\
\hline Copper & 0.0097 & 0.11 & 0.022 \\
\hline Iron & $<0.0050$ & 12 & 2.6 \\
\hline Lead & $<0.050$ & 0.090 & $<0.050$ \\
\hline Lithium & 0.050 & 0.051 & 0.052 \\
\hline Magnesium & 13 & 13 & 13 \\
\hline Manganese & 0.029 & 0.089 & 0.031 \\
\hline Mercury & $<0.0008$ & $<0.0002$ & $<0.0002$ \\
\hline Molybdenum & 0.019 & 0.033 & 0.038 \\
\hline Nickel & 0.016 & 0.030 & 0.066 \\
\hline Niobium & $<0.0070$ & $<0.0070$ & 0.027 \\
\hline Phosphorus & $<0.20$ & 2.2 & 2.2 \\
\hline Polassiam & 5.6 & 5.5 & 5.6 \\
\hline Silicon & 5.5 & 5.2 & 4.7 \\
\hline Silver & $<0.0060$ & $<0.0060$ & $<0.0060$ \\
\hline Sodium & 450 & 440 & 440 \\
\hline Strontium & 0.15 & 0.17 & 0.14 \\
\hline Thorium & $<0.20$ & $<0.20$ & $<0.20$ \\
\hline Titanium & $<0.0030$ & 0.022 & 0.010 \\
\hline Uranium & 0.60 & 1.00 & 1.03 \\
\hline Vanadium & $<0.0050$ & $<0.0050$ & 0.0060 \\
\hline Zinc & $<0.00020$ & 0.099 & 0.051 \\
\hline Zirconium & $<0.0050$ & $<0.0050$ & $<0.0050$ \\
\hline
\end{tabular}


Table 20. Simulated CNF removal efficiency (\%)

\begin{tabular}{|c|c|c|c|c|c|c|}
\hline \multirow[b]{2}{*}{ Analysis } & \multirow{2}{*}{$\begin{array}{l}8 / 27 / 90 \\
\text { Batch } 1 \\
\end{array}$} & \multicolumn{2}{|c|}{$1 / 17 / 91$} & \multicolumn{3}{|c|}{$1 / 19 / 91$} \\
\hline & & Batch 1 & Batch 2 & Batch 1 & Batch 2 & Batch 3 \\
\hline Aluminum & 95 & 97 & 90 & 92 & 82 & 94 \\
\hline Barium & 89 & 97 & 62 & 84 & 64 & 66 \\
\hline Beryllium & $>75$ & $>80$ & $I^{b}$ & I & I & I \\
\hline Chromium & $>76$ & $>85$ & $>70$ & 78 & $>74$ & 86 \\
\hline Copper & 90 & 96 & 74 & 80 & 57 & 56 \\
\hline Manganese & 98 & 88 & 59 & 52 & 0 & 6 \\
\hline Nickel & $>70$ & 72 & 36 & 65 & 23 & 76 \\
\hline Phosphorus & 91 & 76 & 55 & 94 & $>92$ & $>91$ \\
\hline Lead & $>80$ & $>71$ & I & $>71$ & $>10$ & 1 \\
\hline Uranium & 98 & 81 & 67 & 35 & 40 & 42 \\
\hline $\begin{array}{l}\text { Iron added } \\
(\mathrm{mg} / \mathrm{L})^{c}\end{array}$ & 13.8 & 30 & 1.8 & 9.7 & 10.2 & 9.4 \\
\hline
\end{tabular}

${ }^{a}$ Removal efficiency computed as $100 \% \times([\mathrm{BT}]-[\mathrm{ATF}]) /[\mathrm{BT}]$, where $[\mathrm{BT}]=$ concentration of sample before treatment and $[\mathrm{ATF}]=$ concentration after treatment with $\mathrm{Fe}$ and filtration through 0.5- $\mu \mathrm{m}$ medium; see Tables 13-17.

${ }^{b}$ Indeterminate value.

${ }^{c}$ Computed as the iron concentration in the treated, preserved sample [ATP] minus the concentration before treatment [BT]. 
Table 21. CNF samples after treatment, filtered

\begin{tabular}{|c|c|c|c|c|c|c|}
\hline \multirow[b]{2}{*}{ Sample ID } & \multicolumn{2}{|c|}{$1 / 17 / 91$} & \multicolumn{3}{|c|}{$1 / 19 / 91$} & \multirow[b]{2}{*}{$\begin{array}{l}\text { Regulatory } \\
\text { standard }\end{array}$} \\
\hline & $\begin{array}{c}\text { Batch 1 } \\
910122- \\
108\end{array}$ & $\begin{array}{c}\text { Batch 2 } \\
910211- \\
106\end{array}$ & $\begin{array}{c}\text { Batch } 1^{b} \\
910211-113\end{array}$ & $\begin{array}{c}\text { Batch 2 } \\
910211-104\end{array}$ & $\begin{array}{c}\text { Batch 3 } \\
910211-109\end{array}$ & \\
\hline Aluminum & 0.032 & 0.030 & 0.032 & 0.055 & 0.021 & \\
\hline Barium & 0.013 & 0.015 & 0.0079 & 0.0096 & 0.071 & $1.0^{c}$ \\
\hline Cadmium & $<0.0030$ & $<0.003$ & 0.003 & 0.0086 & $<0.003$ & $0.01^{c}$ \\
\hline Chromium & $<0.010$ & $<0.010$ & 0.0016 & $<0.010$ & 0.011 & $0.05^{c_{d} d}$ \\
\hline Copper & 0.0051 & 0.0058 & 0.0094 & 0.012 & 0.0097 & $1.0^{\circ}$ \\
\hline Lead & $<0.050$ & $<0.050$ & $<0.050$ & $<0.050$ & $<0.050$ & $0.05^{c}$ \\
\hline Nickel & 0.036 & 0.030 & 0.025 & 0.023 & 0.016 & \\
\hline Silver & 0.006 & 0.0077 & & $<0.0060$ & $<0.006$ & \\
\hline Zinc & 0.0066 & 0.011 & 0.014 & 0.010 & $<0.002$ & $5.0^{c}$ \\
\hline Iron & 0.01 & 0.014 & 0.022 & 0.011 & 0.005 & $0.3^{e}$ \\
\hline Manganese & 0.025 & 0.026 & 0.034 & 0.045 & 0.029 & $0.05^{e}$ \\
\hline Mercury & $<0.002$ & 0.0008 & 0.0008 & $<0.0008$ & 0.008 & $0.002^{\mathfrak{c}}$ \\
\hline Uranium & 0.18 & 0.21 & 0.64 & 0.62 & 0.60 & \\
\hline
\end{tabular}

"<" means that the values were at the detection limits of the instrument for the conditions of the analysis.

${ }^{b}$ Mixture with sump water from runs previous to the air test.

'EPA interim primary drinking water standard (maximum).

${ }^{d}$ Drinking water standard limit for hexavalent chromium [Cr(VI)].

${ }^{\circ}$ EPA proposed secondary drinking water standard (maximum). 


\section{EXAMINATION OF ASH WATER AND ASH MATERIAL}

The estimated ash content of the liquid feeds to the incinerator during both emissions tests was low, as would be expected of liquid feeds: $0.47 \%$ in Tank 305A; $1.3 \%$ in Tank 306A; and $1.85 \%$ in Tank $307 \mathrm{~A}$. Total ash from the first run would be predicted to be $27 \mathrm{lb}(12,000 \mathrm{~g})$ and from the second run, $27 \mathrm{lb}(12,000 \mathrm{~g})$. The two tests followed several weeks after the kiln had been refitted with refractory brick and a general maintenance had been performed. Nonetheless, contamination of this ash from long past, as well as immediate past, runs is probable.

The results irom the 1-16-91 run are shown in Table 22 and from the 1-18-91 test, in Table 23. During the first run, two samples of the particles were taken and labelled ASH1 and ASH2; a sample of ash blowdown water was also taken, labelled AW. ASH1 contained detritus from the kiln brick renewal project and from operations of many prior months. ASH 2 sample was taken several hours into the run with the hope it would reflect more current operating conditions. As in the August 1990 air test, the ash showed that aluminum, phosphorus, and iron were predominant species. However, unlike the August 1990 test, calcium was found in macroscopic amounts in the January emissions test. No analytical results are available on air emissions from the August test. The filtered ash water showed only trace concentrations of these four elements (aluminum, phosphorus, iron, and calcium) and, in fact, showed concentrations of species of water quality regulatory concern lower than in the scrubber water. The possible exception is manganese, as can be seen from a comparison of Tables 7 and 8 and Tables 22 and 23. 
Table 22. Results of analyses of TSCA waters-1-16-91 run

\begin{tabular}{|c|c|c|c|}
\hline Element & $\begin{array}{c}\text { TS-011691-ASH1 } \\
910126-114 \\
(\mu \mathrm{g} / \mathrm{g})\end{array}$ & $\begin{array}{c}\text { TS-011691-ASH2 } \\
910126-115 \\
(\mu \mathrm{g} / \mathrm{g}) \\
\end{array}$ & $\begin{array}{c}\text { TS-011691-AW (ash } \\
\text { water) } 910126-117 \\
(\mu \mathrm{g} / \mathrm{L})\end{array}$ \\
\hline Aluminum & 40,000 & 22,000 & 1.6 \\
\hline Antimony & & & $<0.050$ \\
\hline Barium & 160 & 82 & 0.053 \\
\hline Beryllium & 25 & 23 & 0.0022 \\
\hline Boron & 16 & 15 & 0.019 \\
\hline Cadmium & $<2.2$ & 1.7 & $<0.0030$ \\
\hline Calcium & 86,000 & 58,000 & 45 \\
\hline Chromium & 1600 & 170 & 0.039 \\
\hline Cobalt & 17 & 14 & $<0.0050$ \\
\hline Copper & 160 & 220 & 0.064 \\
\hline Iron & 34,000 & 27,000 & 14 \\
\hline Lead & 78 & 97 & 0.085 \\
\hline Lithium & 44 & 36 & 0.0089 \\
\hline Magnesium & 5900 & 6100 & 13 \\
\hline Manganese & 460 & 320 & 0.11 \\
\hline Mercury & & & $<0.0004$ \\
\hline Molybdenum & 34 & 12 & 0.012 \\
\hline Nickel & 2200 & 1900 & 0.05 \\
\hline Niobium & $<5.2$ & 0.8 & $<0.0070$ \\
\hline Phosphorus & 20,000 & 14,000 & 1.4 \\
\hline Potassium & 1000 & 780 & 1.9 \\
\hline Sillicon & 390 & 270 & 5.6 \\
\hline Silver & $<4.4$ & $<0.49$ & 0.0075 \\
\hline Sodium & 1700 & 1500 & 7.3 \\
\hline Strontium & 320 & 200 & 0.15 \\
\hline Thorium & $<150$ & $<16$ & $<0.20$ \\
\hline Titanium & 680 & 490 & 0.062 \\
\hline Uranium & & & $<0.1$ \\
\hline Vanadium & 32 & 20 & 0.0068 \\
\hline Zinc & 370 & 340 & 0.089 \\
\hline Zirconium & $<3.74$ & 1.8 & $<0.00 .50$ \\
\hline
\end{tabular}


31

Tuble 23. Results of analyses of TSCA waters-1-18-91 run

\begin{tabular}{|c|c|c|}
\hline Analysis & $\begin{array}{c}\text { TS-011891-ASH } \\
910126-116 \\
(\mu \mathrm{g} / \mathrm{g})\end{array}$ & $\begin{array}{c}\text { TS-011891-AW (ash } \\
\text { water) 910126-120 } \\
(\mu \mathrm{g} / \mathrm{g})\end{array}$ \\
\hline Aluminum & 16,000 & 0.41 \\
\hline Antimony & & $<0.050$ \\
\hline Barium & 91 & 0.040 \\
\hline Beryllium & 18 & 0.00046 \\
\hline Boron & 210 & 0.014 \\
\hline Cadmium & $<5.0$ & $<0.0030$ \\
\hline Calcium & 45,000 & 35 \\
\hline Chromium & 110 & $<0.01 \mathrm{C}$ \\
\hline Cobalt & 14 & $<0.00500$ \\
\hline Copper & 200 & 0.012 \\
\hline Iron & 56,000 & 5.7 \\
\hline Lead & 160 & $<0.050$ \\
\hline Lithium & 31 & 0.0061 \\
\hline Magnesium & 5200 & 11 \\
\hline Manganese & 460 & 0.0051 \\
\hline Mercury & & $<0.0002$ \\
\hline Molybdenum & $<17$ & $<0.010$ \\
\hline Nickel & 1100 & 0.025 \\
\hline Niobium & 124 & $<0.0070$ \\
\hline Phosphorus & 12,000 & 0.50 \\
\hline Potassium & 1000 & 2.0 \\
\hline Silicon & 2800 & 2.8 \\
\hline Silver & $<10$ & $<0.0060$ \\
\hline Sodium & 1900 & 7.5 \\
\hline Strontium & 170 & 0.11 \\
\hline Thorium & $<330$ & $<0.020$ \\
\hline Titanium & 730 & 0.018 \\
\hline Uranium & 19 & $<0.1$ \\
\hline Vanadium & & $<0.0050$ \\
\hline Zinc & 360 & 0.035 \\
\hline Zirconium & 65 & $<0.0050$ \\
\hline
\end{tabular}




\section{NOTES ON SAMPLE PREPARATION AND ANALYSIS TECHNIQUES}

As noted earlier, new sample preparation techniques have recently been implemented. Most samples discussed in this report contained a liquid (organic or aqueous), as well as solid, phase. The available ICP atomic emission spectrometer and the atomic absorption spectrometer accept only homogeneous liquid samples. Solids, if present, must be dissolved, and this is often difficult to accomplish. The as-received samples are shaken to provide homogeneous aliquots to deliver to other analytical laboratories. In the case of a sample that is more difficult to homogenize, an ultrasonic technique is used. In an organic matrix, the technique formerly generally used for metals analysis and still used for uranium is known as the Parr bomb. In the Parr bomb, the sample is oxidized in a stainless steel armor-plated vessel using a platinum wire as a heat source under high pressure. It was never intended to prepare a variety of elements; the bomb corrodes when chlorine is present and gives high values of chromium, for example. There are difficulties with the sample splattering.

The High-Pressure Asher (HPA) for organic samples has also been developed within the last year and come into routine use at the K-25 Site in the last several months, although it was used in August 1990 emissions testing to prepare samples for radionuclide analysis. It is a high-pressure (100-bar) acid dissolution technique performed in a quartz vessel requiring approximately $6 \mathrm{~h}$. Less development has been done with it, and the recovery of certain metals (silver, antimony, titanium, and others that form insoluble chlorine compounds) is uncertain or nonreproducable. The HPA is better than its Parr bomb predecessor in retaining volatile elements because of its high-pressure operation.

Ash samples were digested using EPA Procedure Method 3050, which covers the acid digestion of sediments, sludges, and soils. It consists of a two-step dissolution: (1) digestion in nitric acid and hydrogen peroxide and (2) a refluxing in nitric or hydrochloric acid.

IWS, quench, and ash waters were all treated using another EPA procedure, Method 3010, which covers acid digestion of aqueous samples and extracts for total metals for analysis by flame atomic absorption or ICP spectroscopy. It consists of a nitric acid reflux followed by a hydrochloric acid reflux. 


\section{CONCLUSIONS}

The conclusions from these emissions tests are, in general. favorable to the operation of the incinerator and its wastewater treatment facility. In an extensive analysis of five batches of aqueous effluent from the CNF after treatment, no metal concentration fell outside regulatory limits. The only close case was manganese in one batch. Most aqueous metal concentrations were comparable to or slightly higher than those in the August 1990 experiment.

The partition of metals to the quench blowdown were, in general, comparable between the August 1990 and the January 1991 tests, except for nickel, chromium, and uranium, all of which were fed in larger amounts in the 1990 experiment. The partition coefficients were actually smaller when the feed quantities were larger. The partition coefficient of uranium to the stack on January 18 was 0.0039 .

Particulate size analysis, performed for the first time on the actual aqueous scrub solutions, appears to be reliable and consistent with dry particulate data. The data indicate that the IWS is operating and removing particulate of an average diameter in the range of $2.3 \mu \mathrm{m}$. Many of the ash particulates are spherical, which suggests that they fused during incineration, as is the case for coal fly ash during combustion.

The partition coefficient of uranium to the quench water was 0.3 on January 16 and 0.35 on January 18; so directing Tank 306A to the feed to the primary vs the secondary combustion chamber appears to have made little difference. Of course, this result is ambiguous because the other feeds to the incinerator were different in the two runs. Uranium may be better captured in the kiln bottom ash if uranium-containing feed is introduced into the kiln along with other waste that is also high in ash, thus increasing the volume of ash available to contain uranium. 


\section{REFERENCES}

1. W. D. Bostick et al., "Effluent Testing for the Oak Ridge Mixed Waste Incinerator," Proceedings, 1991 Incineration Conference, Knoxville, Tennessee, May 13-17, 1991.

2. E. Raask, Mineral Impurities in Coal Combustion, Hemisphere, 1985, p. 63.

3. CRC Handbook of Chemistry and Physics, 52nd ed., Chemical Rubber Company, Cleveland, Ohio, 1971. 
Appendix A

MICROCHARACTERIZATION OF THE TOXIC SUBSTANCES CONTROL ACT MIXED WASTE INCINERATOR EFFLUENT PARTICULATES 


\section{BACKGROUND}

This appendix contains the results of scanning electron microscopy (SEM) and energy dispersive X-ray spectroscopy (EDS) of samples of solids collected during Toxic Substances Control Act (TSCA) Incinerator operations from the quench and ionizing wet scrubber (IWS) liquors and fly ash from the stack during the January 18, 1991, emissions test. Also presented are EDS results from the solids from TSCA wastewaters sent to the Central Neutralization Facility (CNF) for treatment. It should be noted that all samples except those from the stack were obtained from solids suspended in a liquid. Data on particle size distribution of TSCA scrubber and stack particulates are presented and can be compared with some data from the main body of the report.

The purposes of this aspect of the emissions test were manyfold: (1) to determine if some correlation could be made between the incinerator feed and the CNF effluents after treatment, (2) to obtain data on the particle size distribution of the solids in the TSCA quench and IWS waters to establish the efficiency of the scrubbers, (3) to determine for the first time the particle size distribution of particles in the flue gas, and (4) to find correlations such as might occur in the data between the two series of analyses, inductively coupled plasma atomic emission spectroscopy (ICP) and EDS.

Quantitative elemental distributions are presented insofar as possible by the standardless semiquantitative (SSQ) EDS analysis, which is limited to elements of atomic number greater than that of sodium, (i.e., $Z>11$ ). Sensitivity is less with lighter elements. In general, the lower limit of the sensitivity of EDS is $1 \mathrm{wt} \%$. (An average reading over an area of $6 \mathrm{~mm}^{2}$ at $10 \mathrm{X}$ by SEM was made to provide the EDS spectra.) The particle size distributions were determined using an automated image analyzer in conjunction with SEM.

\section{SAMPLE PREPARATION}

Samples suspended in liquid (quench and IWS blowdown samples) were prepared in the following manner: The contents of the container were first sonicated (i.e., subjected to ultrasonic vibrations) for $5 \mathrm{~min}$, and a $10-\mathrm{mL}$ aliquot was removed. Forty milliliters of distilled $\mathrm{H}_{2} \mathrm{O}$ were added to the aliquot, which was again sonicated for $5 \mathrm{~min}$ and then centrifuged for 5 min. The supernate was decanted. This aliquot wash cycle was performed three times. Soluble compounds (including sodium chloride) were believed to be well rinsed during this treatment. Freon was then added to the aliquot, the sample was sonicated for $10 \mathrm{~min}$, and a portion of it was removed to disperse on a planchette. The planchette was then carbon coated for SEM.

The stack sample, as discussed in Sect. 3.2 of the main body of the text, was collected on a specially carbon-coated millipore filter (the carbon coating was provided to aid in SEM analysis). The millipore filter was blanked off except for a 1-in.-diam section; however, in the field the blanking had no effect, and the particulate spread to cover the entire area of the filter. A subsample was taken and added to $10 \mathrm{~mL}$ of Freon, sonicated, and an aliquot again dispersed on a planchette for carbon coating and SEM observation. 


\section{RESULTS}

\section{ELEMENTAL ANALYSES}

\section{Scrubber Liquors}

The results of the EDS analysis of the TSCA scrubber liquors are shown in Table A.1. The results are from the solids contained in the quench (QBD) and the IWS purge streams. Listed are the most common, predominant metals of the SSQ-EDS analysis. Th, actual spectra are shown in Figs. A.1 and A.2, and the presence of several trace species such as aluminum, sodium, and carbon (not quantified) can be noted. Unlike the EDS sample, the sample analyzed by ICP spectroscopy contained the homogenized metals from the dissolved liquid phase as well as the undissolved solids. The digestion technique used to prepare the samples for ICP spectroscopy was not believed to be effective in recovering silicon; yet the ICP results are qualitatively very consistent with those of the EDS. Chlorine cannot be detected by ICP analysis. Most other metals detected by the EDS were also present in quantities above $1 \mathrm{ppm}$ in the ICP analysis. The exceptions were magnesium and potassium, which are detected only with low sensitivity by EDS. The two analytical techniques are therefore fairly consistent and somewhat complementary, within their respective limitations.

The relative concentrations of metals in many cases were quite different. For example, in the IWS, the ratio of $\mathrm{Zn:Pb}$ by EDS was $2.7: 1$ and by ICP, 0.93:1; and the ratio of $\mathrm{Ca}$ to Fe by EDS was $0.62: 1$ and by ICP, 3.0:1. This may reflect variations in solubility of the metals and imprecision in the semiquantitative EDS analysis. The absence of chlorine in the IWS EDS analysis is attributed to its removal, as soluble compounds, from the sample during preparation. Chlorine in the quench sample may be indicative of poorer washing efficiency.

The greater concentrations of silicon, potassium, zinc, and lead in the IWS particulate as compared with the QBD may be consistent with the higher volatility of these metals (compared with iron, calcium, and uranium) and the formation of finer particles containing these metals.

\section{TSCA Stack}

The SSQ-EDS analysis of the predominant stack species is shown in Table A.1. Thu actual spectrum is shown in Fig. A.3. The stack sample, being unwashed, probably more accurately reflects the chlorine concentration than the IWS sample. It is interesting also to note that the stack sample and the IWS sample are nearly identical in uranium concentration. Most significant is the close similarity in chemical composition of the stack particulate and the IWS particulate. In coal combustion, a correlation in chemical composition of fly ash particles has been found; smaller particles are, in general, more concentrated in more volatile species. ${ }^{1}$ Within the bounds of the EDS accuracy, no such trend can be discerned in these data. This fact will also be consistent with the particle size data in the next section.

${ }^{1}$ R. L. Davison, et. al., Environmental Science and Technology 8 (3), 1107 (1974). 
Table A.1. EDS analysis for TSCA effluent particulates

\begin{tabular}{lccc}
\hline \multicolumn{1}{c}{ Element } & QBD wt \% & IWS wt \% & STK wt \% \\
\hline Silicon & 9.8 & 29.9 & 14.3 \\
Phosphorus & 9.5 & 21.4 & 9.0 \\
Chlorine & 0.2 & 0.0 & 9.9 \\
Potassium & 1.2 & 4.8 & 6.5 \\
Copper & 56.8 & 12.1 & 27.5 \\
Iron & 19.0 & 19.4 & 22.3 \\
Zinc & 1.5 & 4.9 & 5.9 \\
Lead & 0.9 & 1.8 & 0.03 \\
Uranium & 1.2 & 3.7 & 3.1 \\
\hline
\end{tabular}




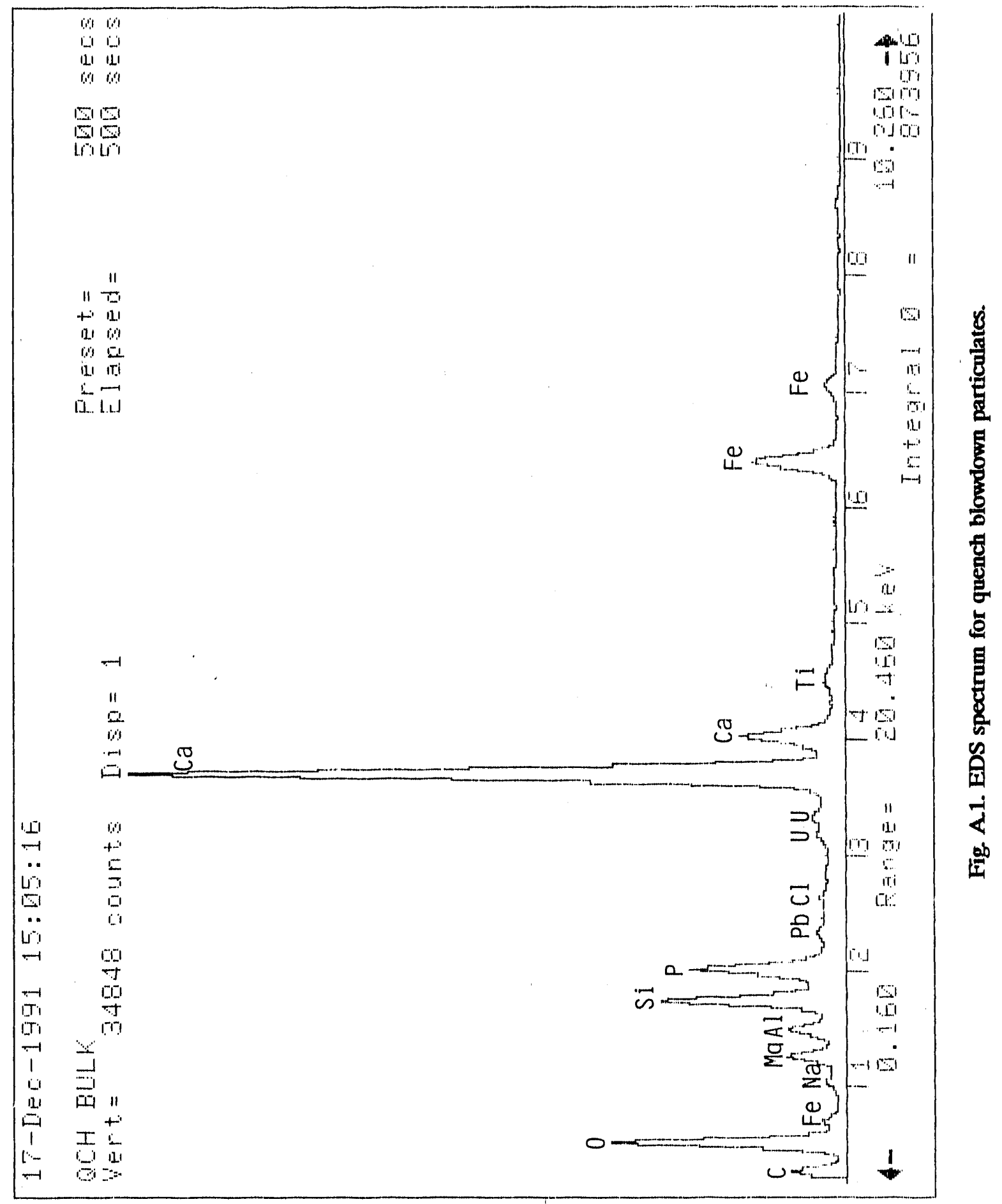




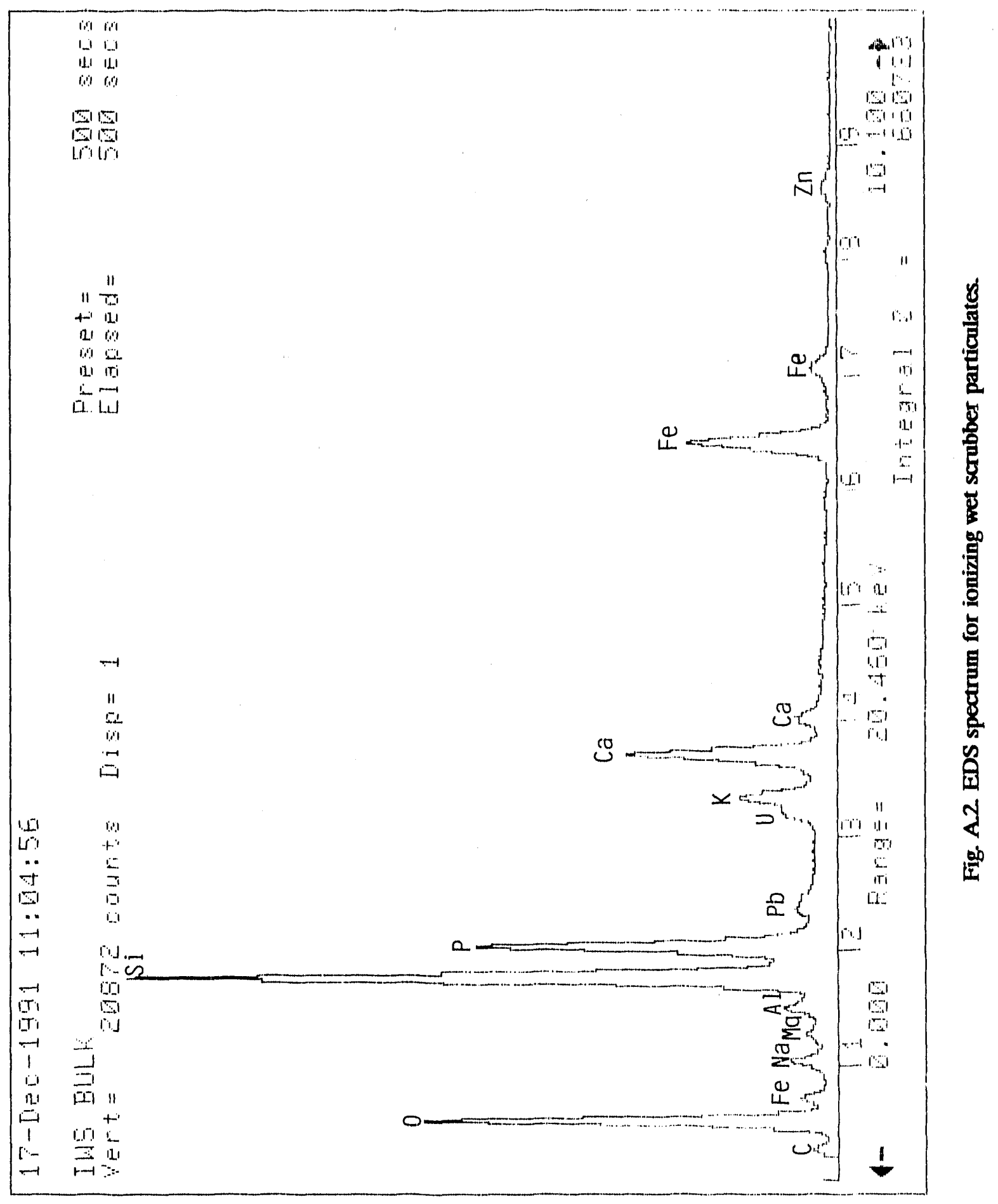




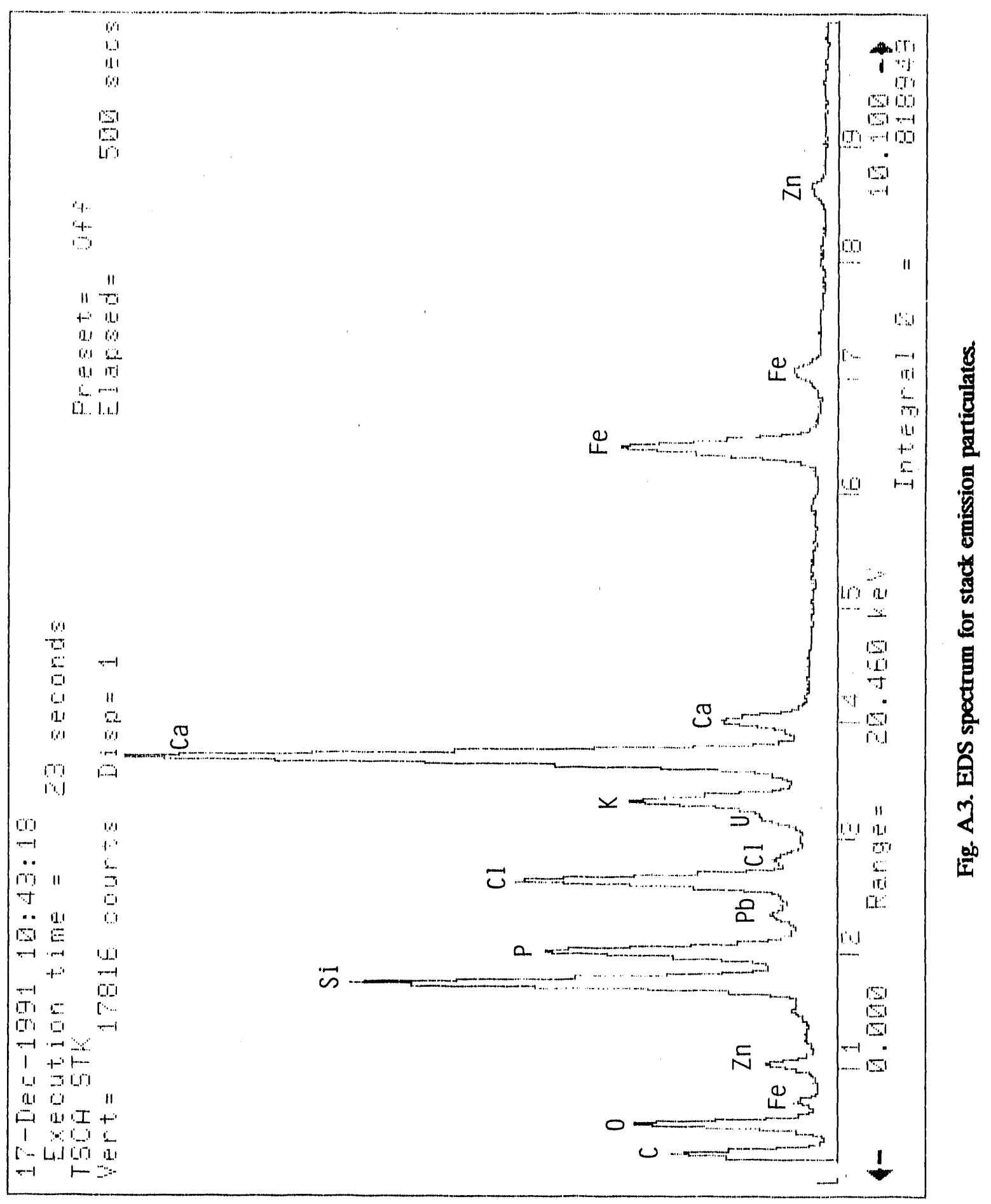




\section{PARTICLE ANALYSES}

\section{Scrubber Waters and Stack Samples}

Table A.2 summarizes the particle size data from the scrubber liquors and the stack sample. As noted, these data were obtained using an automated image analyzer, which counts the number of pixels within a given region to determine its area and no assumption of circularity is made. Still, the diameter of an equivalent circle (Waddel) may be calculated from average areas, and this is shown in Table A.2 as the average diameter as well as other relevant data. Equivalent particle diameters may be computed from the cross-sectional area image data, so that the particle distribution data may be processed in a manner analogous to that described in the main text. ${ }^{2}$

Table A.2. Particle size data for TSCA effluen? particulates

\begin{tabular}{lccc}
\hline $\begin{array}{c}\text { Normal distribution } \\
\text { statistics }\end{array}$ & QBD & IWS & STK \\
\hline Avg. area $\left(\mu \mathrm{m}^{2}\right)$ & 1.96 & 0.82 & 1.59 \\
Std. dev. & 2.28 & 1.55 & 2.19 \\
Min. area & 0.55 & 0.06 & 0.06 \\
Max. area & 9.94 & 10.0 & 9.94 \\
Avg. diameter & 1.58 & 1.02 & 1.42 \\
& & & \\
$\begin{array}{l}\text { Log normal } \\
\text { distribution }\end{array}$ & & & \\
statistics & 1.19 & 0.75 & 1.14 \\
$\begin{array}{l}\text { Geometric mean } \\
\text { diameter }\end{array}$ & 1.76 & 1.89 & 1.73 \\
Spread factor & & & \\
\hline
\end{tabular}

The particle size distribution (by area) is shown in Figs. A.4 to A.6 for the QBD and IWS scrubbers and the stack, respectively.

The average particle equivalent diameter was approximately half that found using the backscattering laser microscope (see Table 10 of main text). There may be several reasons for this: The resolution of the electron microscope is much greater and could detect particies that were too small to detect using the laser backscattering technique (i.e., $<0.7 \mu \mathrm{m}$; of Sect. 3.1 of the main text). The image analyzer was set to ignore particles $>10 \mu \mathrm{m}$ in area; hence some of the larger particles were ignored. Thus, particle size analysis by the electron

${ }^{2}$ D. Mackay and S. Peterson, Environmental Science Technology 18, 207A (1984). 


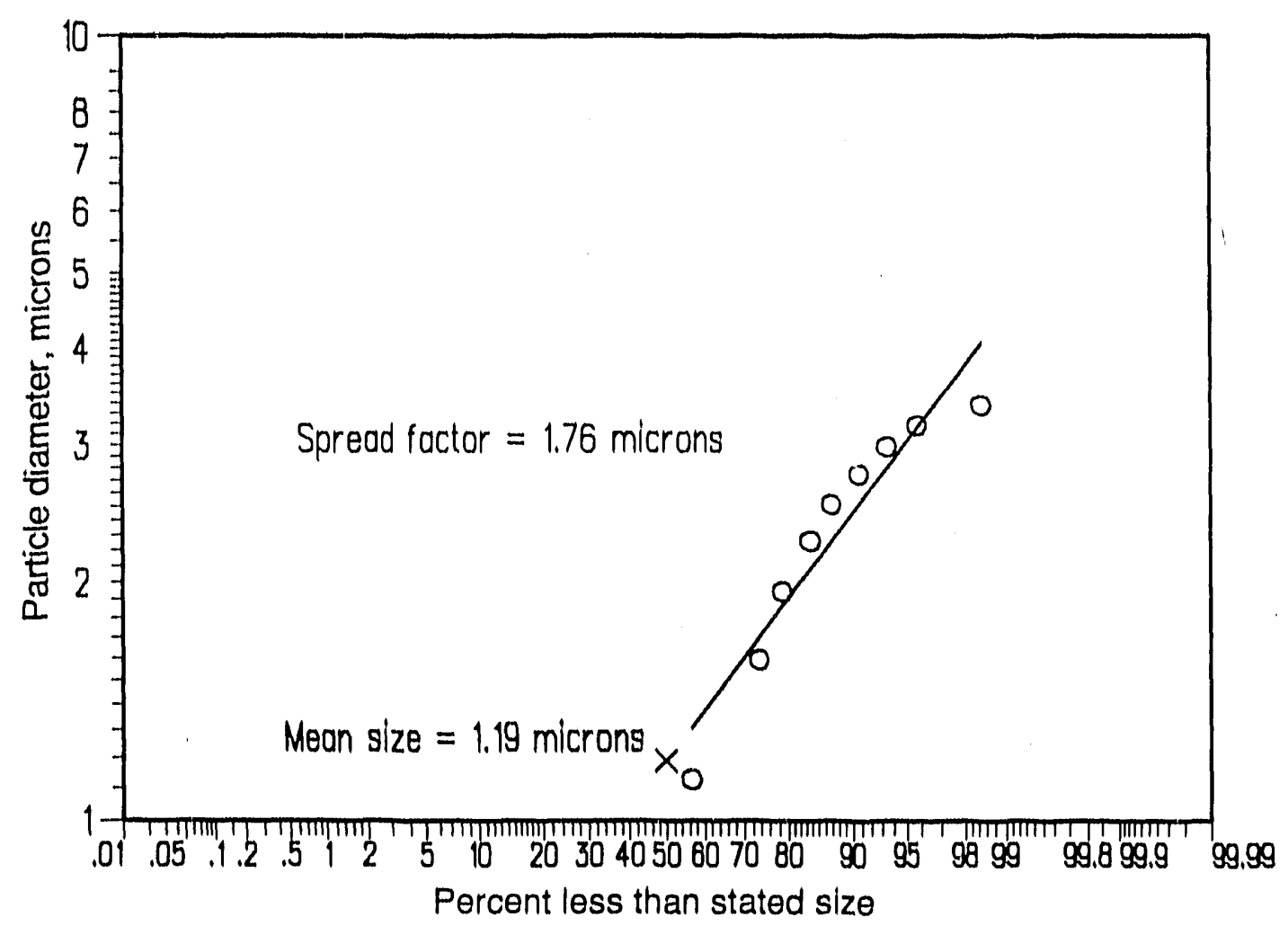

Fig. A.4(a). Particle diameter for quench blowdown solids: log-normal data plot.

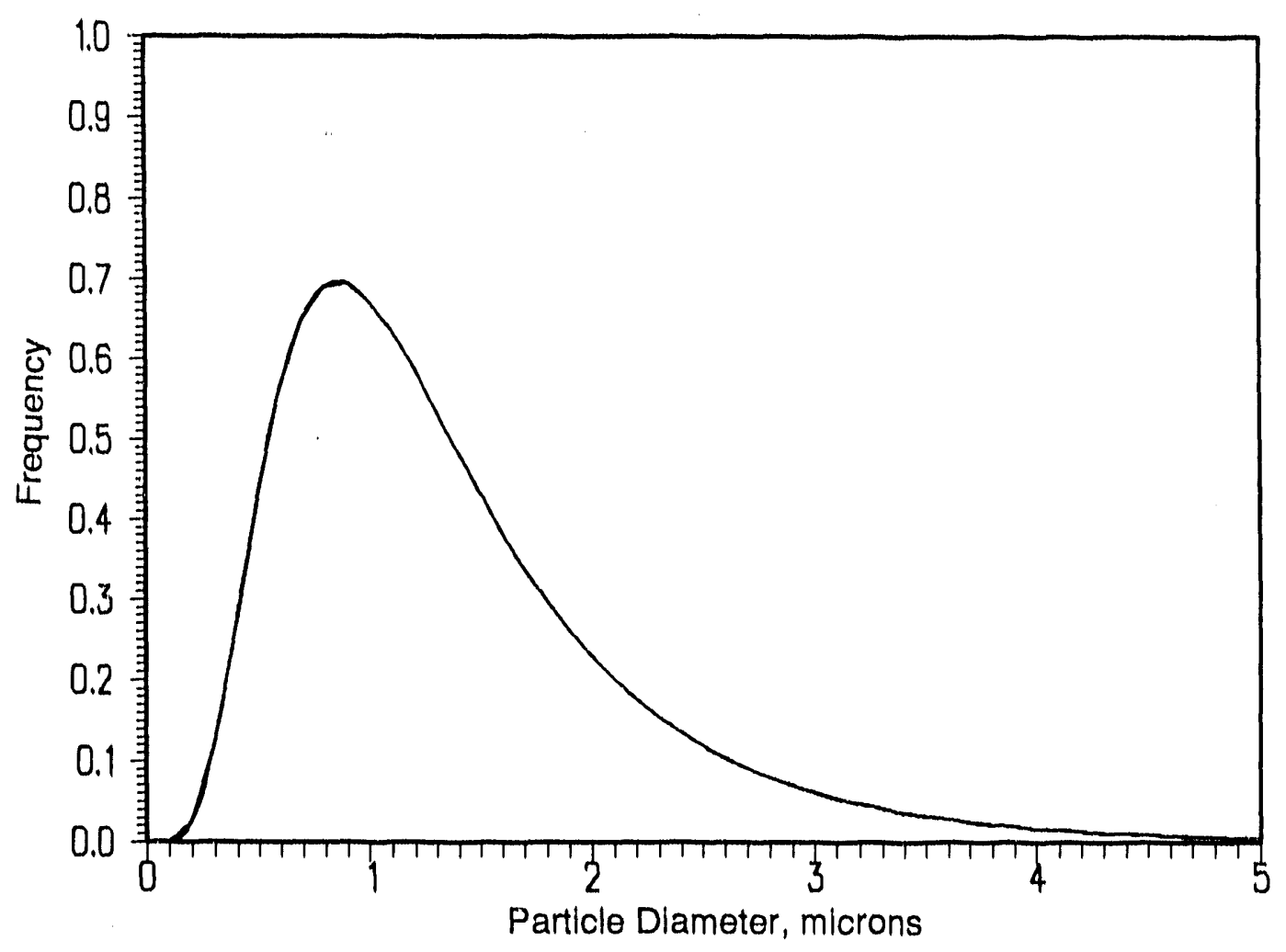

Fig. A.4(b). Particle diameter data for quench blowdown solids: computed distribution. 


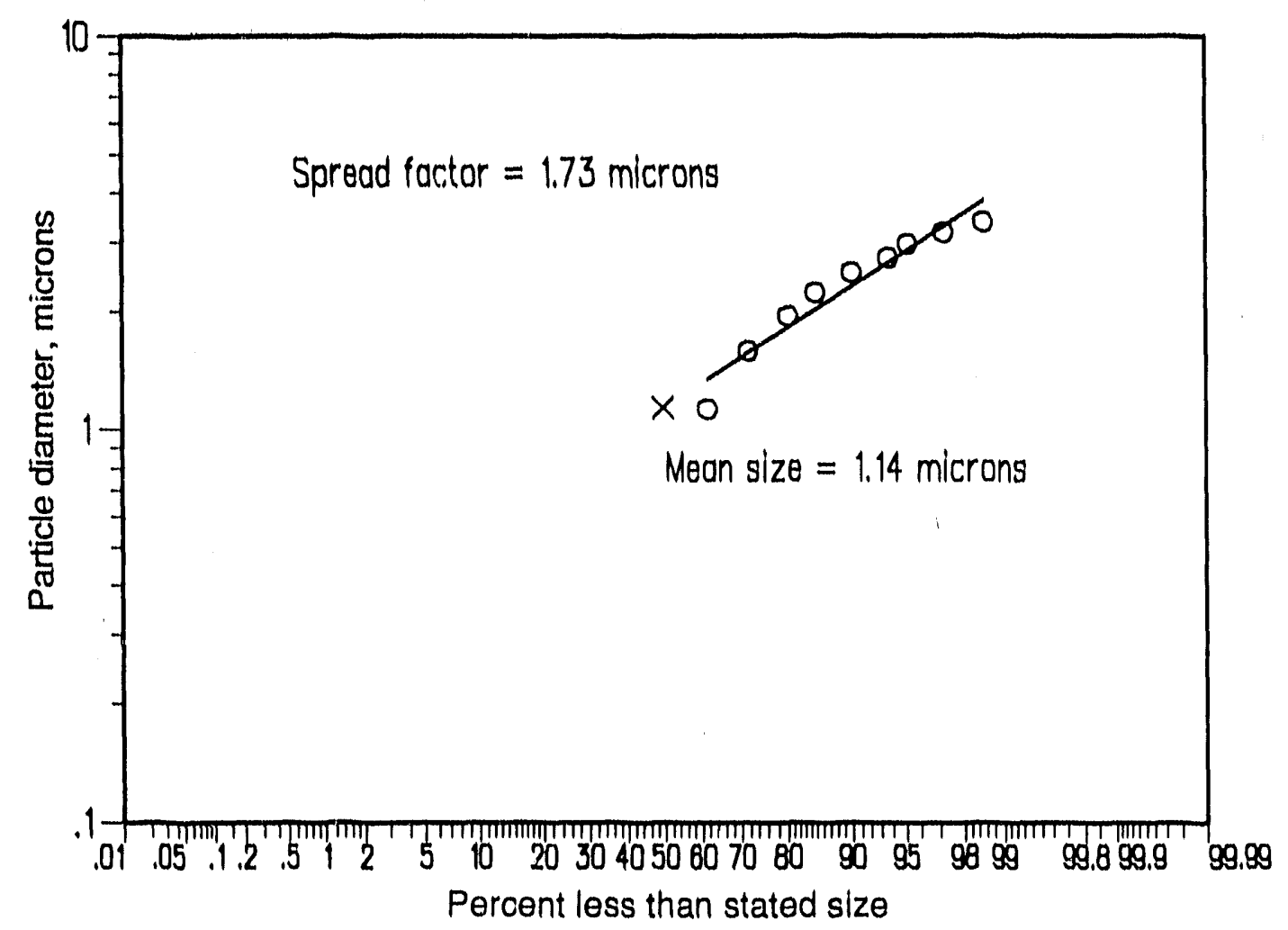

Fig. A.5(a). Particle diameter data for stack emission solids: log-normal data plot.

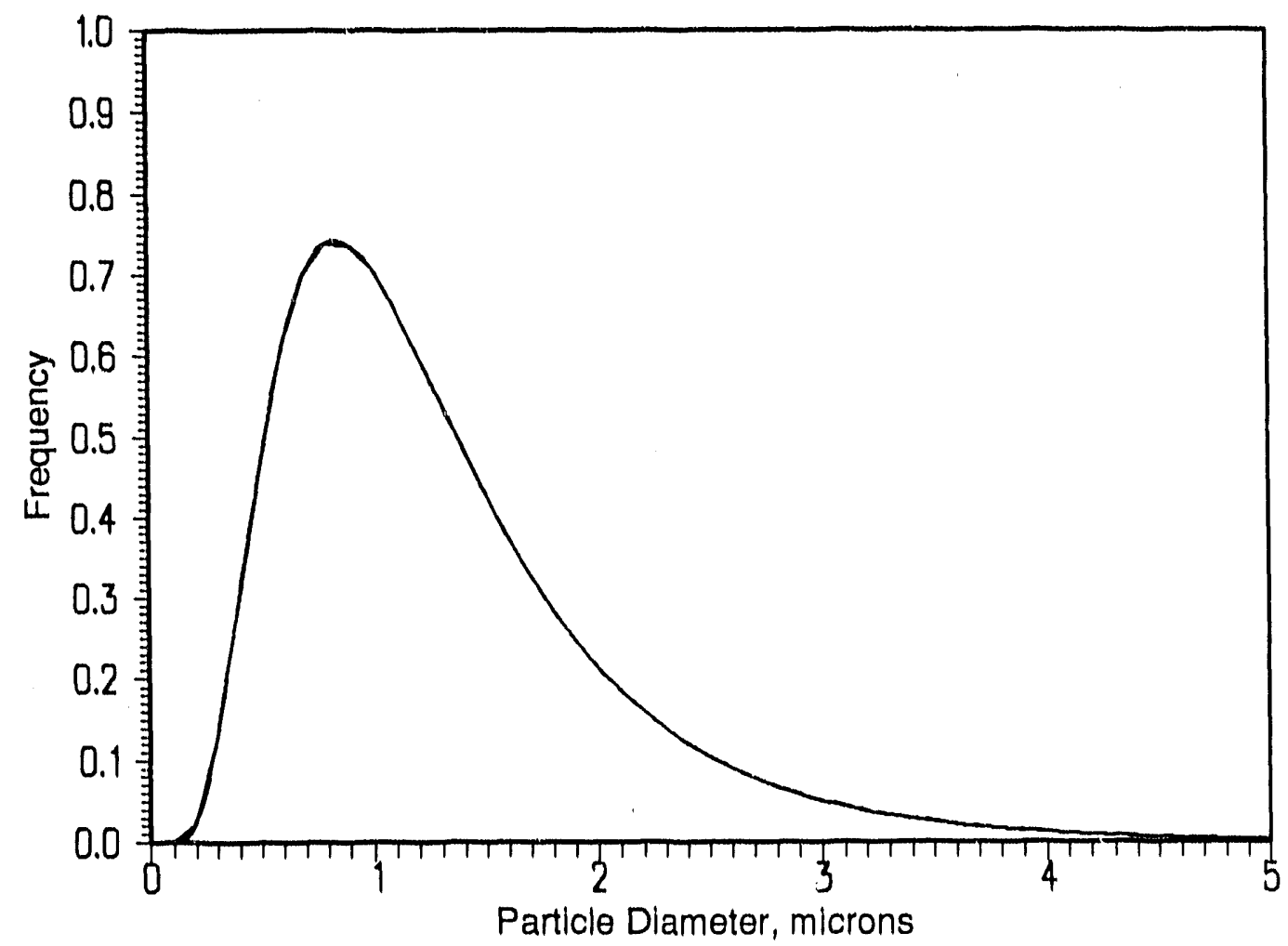

Fig. A.5(b). Particle dianeter data for ionizing wet scrubber solids: computed distribution. 


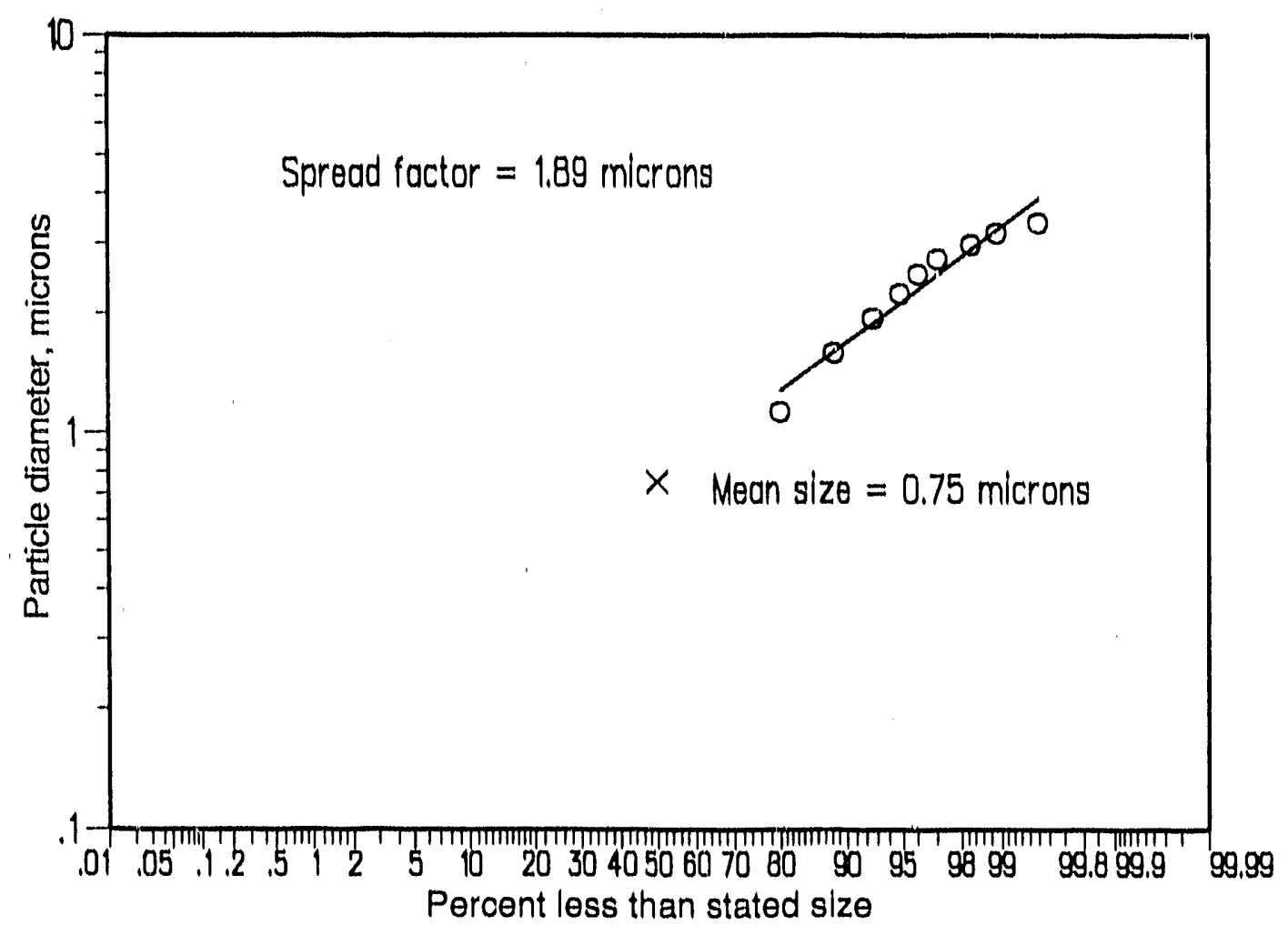

Fig. A.6(a). Particle diameter data for ionizing wet scrubber solids: log-normal data plot.

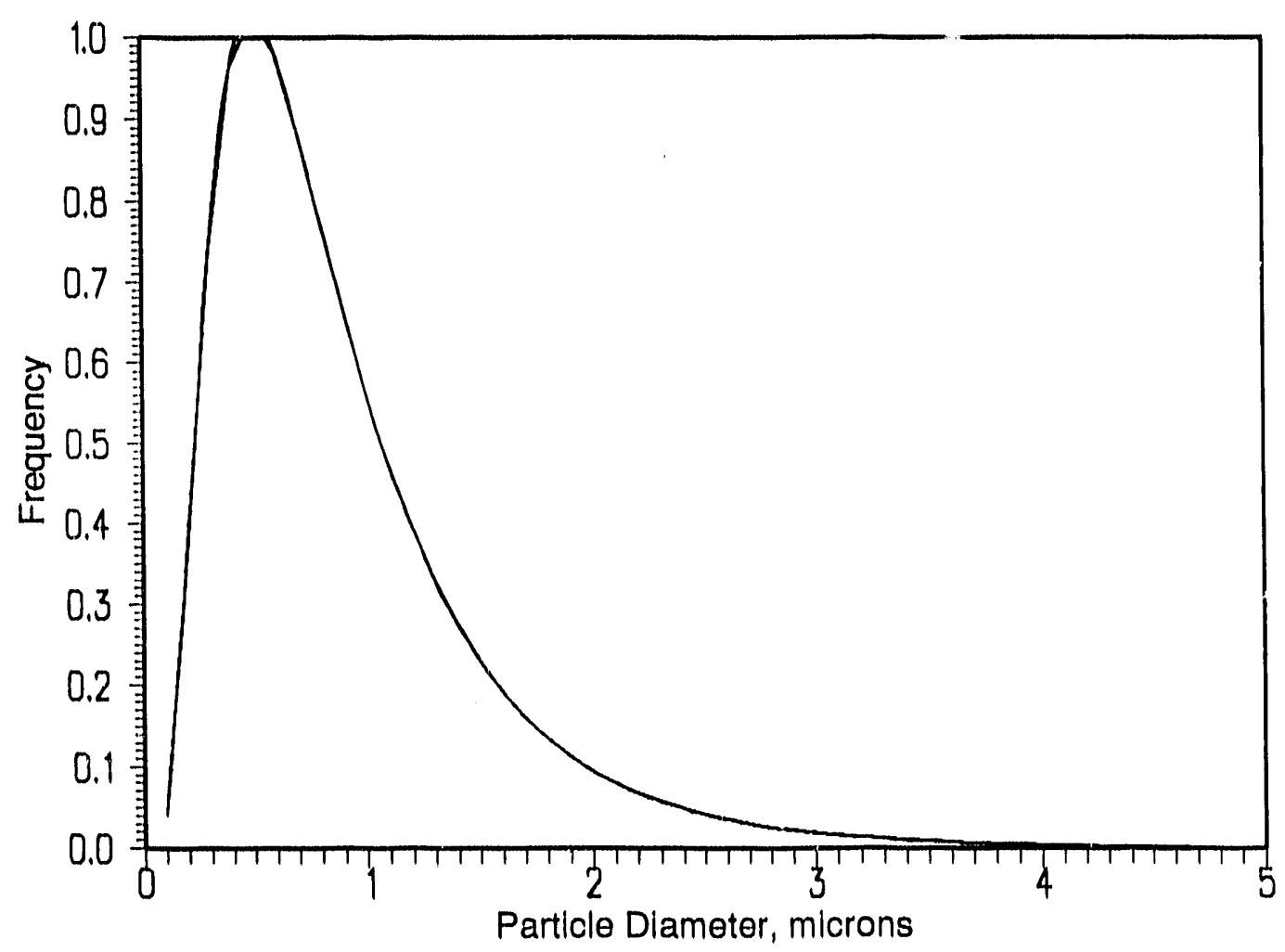

Fig. A.6(b). Particle diameter data for stack emission solids: computed distribution. 
micrograph would be somewhat biased to smaller size domains. Particles of elongated shape such as a cylinder would be improperly counted by the backscattering technique as smaller in area than they actually were. The solvent water of the IWS and QBD samples was removed before analysis. The stack sample was subjected to ultrasunic vibrations (i.e., sonicated). These two factors may yield particles of different dimensions than were actually present in the incinerator gases.

Of particular interest and importance is the similarity of the particle size distribution in the stack and the IWS liquors. The IWS is designed to remove with better than $90 \%$ average efficiency per stage particles $1 \mu \mathrm{m}$ and larger diameter, according to the vendor's literature. The data in Fig. A.6 suggest that this is not occurring, and while there are reasons, as noted, to suspect the data, the distribution in Fig. A.5 suggests that the particles are easily entrained from the IWS to the stack. The distributions are very similar in Figs. A.5 and A.6.

The technique used to collect the stack gas particulate, however, was not a standard EPA technique and may have permitted the particles to agglomerate. Agglomeration would yield an anomalously skewed particle size distribution. The effect of the sonication on this distribution is unknown. The degree of agglomeration in the scrubber waters is also unclear, as well as their proclivity to agglomerate when dried. Electron micrographs of the stack particulates are provided in Figs. A.7(a) and A.7(b) at 1000 and $2000 \mathrm{X}$ magnifications, respectively. Their "fluffy" appearance is their most notable morphological distinction by contrast to the scrubber solids and may result from agglomeration. The quench solids are shown in Figs. A.8(a) and A.8(b) and the IWS solids are shown in Figs. A.9(a) and A.9(b) at the same magnifications. When preparing the particle size distril ution data, it is apparent that larger sample populations were available for the stack and quench statistics and that their geometric standard deviations were smaller than that of the IWS solids.

\section{CNF WATER TREATMENT RESULTS}

The TSCA wastewaters from the scrubber purge were pumped to the CNF in five separate batches, two from the first emissions test dated $1 / 17 / 91$ and three from the second dated 1/19/91. The results of the EDS spectra are listed in Table A.3 along with the batch numbers for comparison with Tables 13 to 19 of the main text, which are all cross-referenced by batch number for either $1 / 17$ or $1 / 19$. These analyses again were made of dried solids, while those in the main text were made of liquids either containing suspended or filtered solids. Batch 1 (1/19/91) was significantly contaminated with waters from the K-1232 Chemical Recovery Facility (believed to contain much calcium) and also from a heel in Tank 240B. The sample, however, does not show any increased concentration of calcium.

The results, in general, are not greatly different from those on the scrubber solids, as would be expected. Sulfur appears here probably because of the addition of iron sulfate, used as a precipitating agent. Batches 1 and $2(1 / 17 / 91)$ taken from J Basin west, after polymer addition, have higher concentrations of carbon than do batches 1,2 , and $3(1 / 19 / 91)$ taken from the bottom of Tank $240 \mathrm{~B}$ at the CNF, before addition of the polymer flocculent. As noted earlier, there is concern that the polymer is not mixing well with the effluent from $240 \mathrm{~B}$, but these data indicate that at least some mixing is occurring. The two samples taken at $J$ Basin have both higher concentrations of sulfur and chlorine than the three samples taken at Tank 240B exit. This may indicate that more highly soluble compounds of chlorine are being flocculated and precipitated, as should occur. 


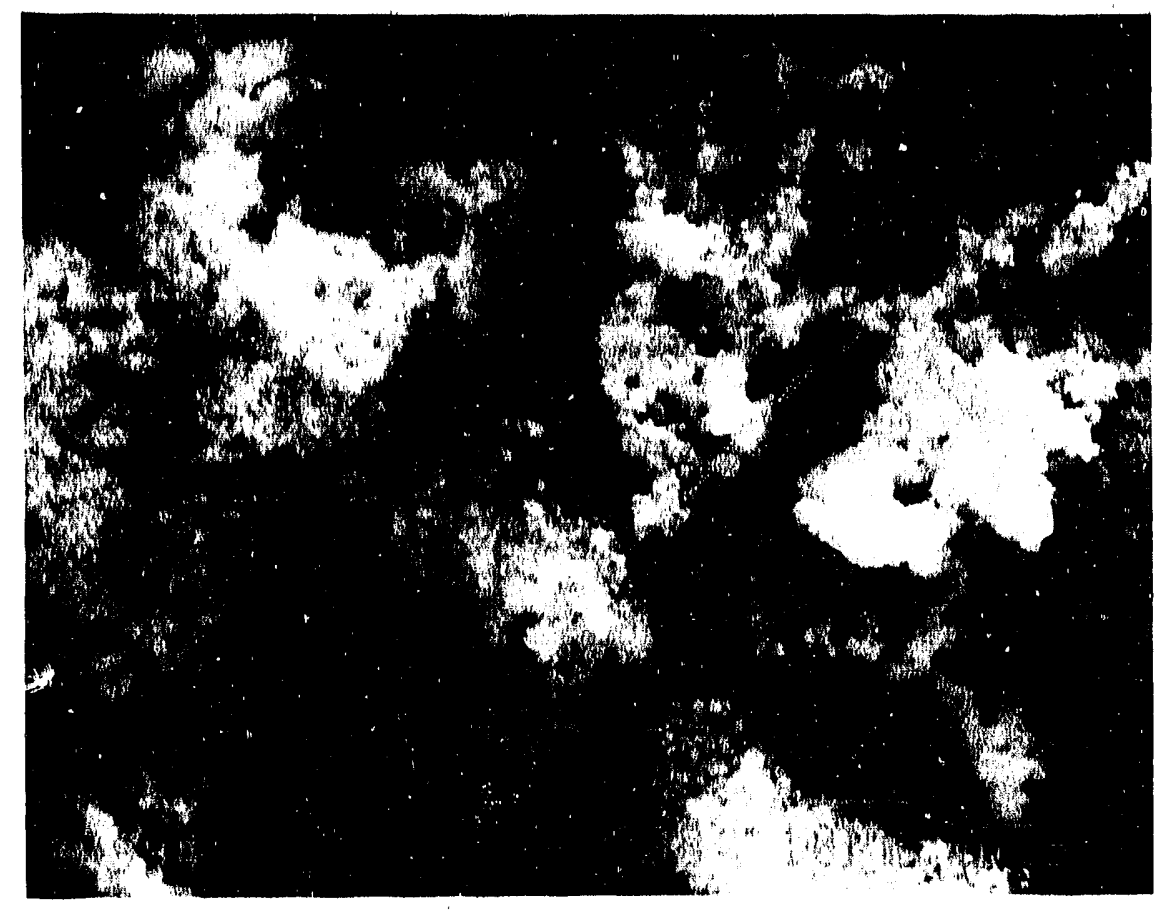

Fig. A.7(a). Micrograph of stack particulates at $1(000 X$.

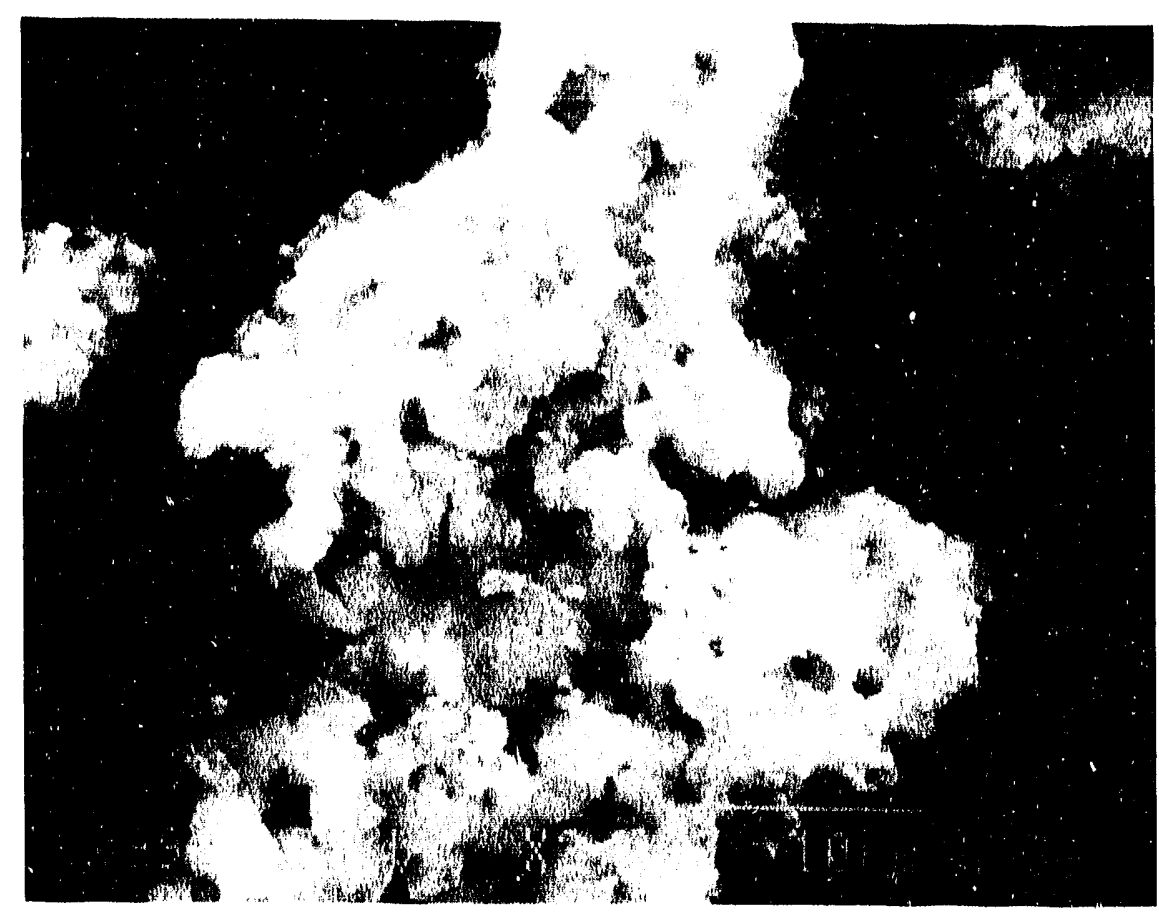

Fig. A.7(b). Micrograph of stack particulates at 2000X. 


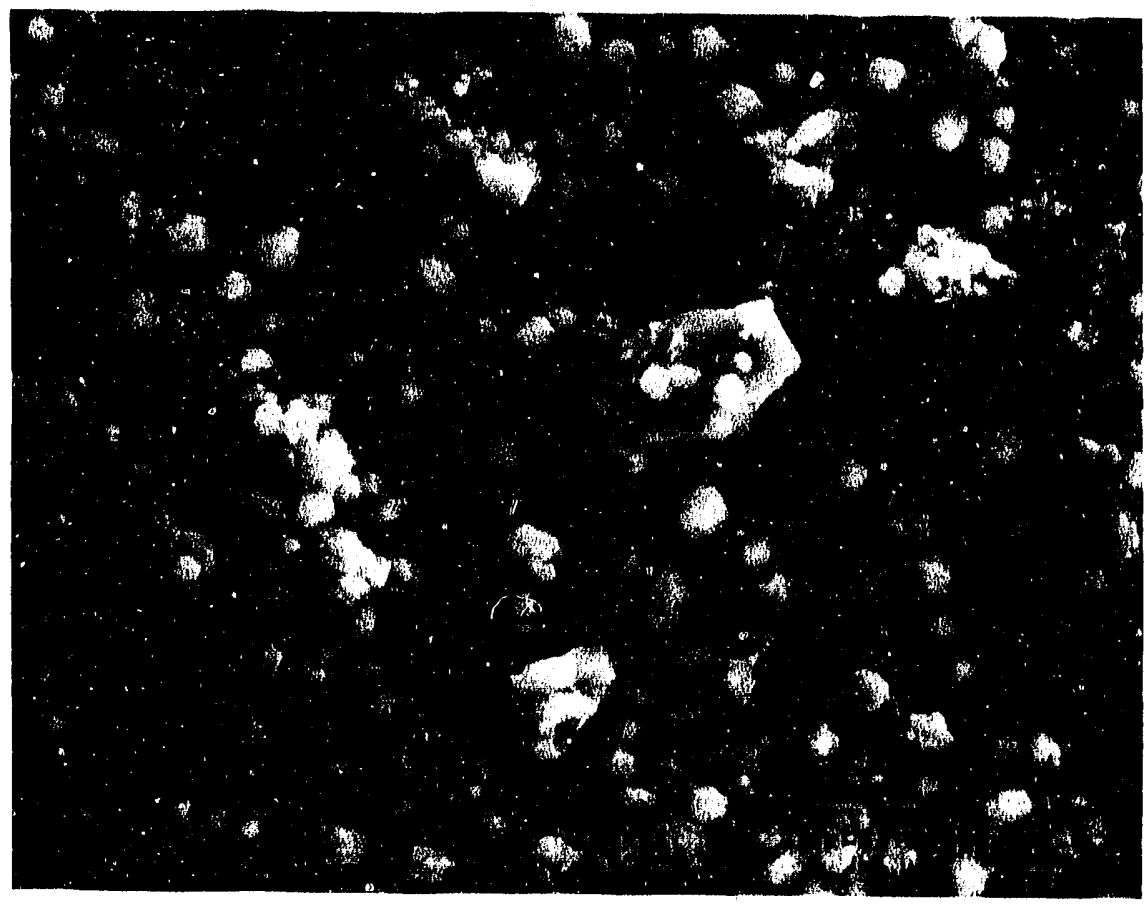

Fig. A.8(a). Micrograph of quench particulates at $1000 \mathrm{X}$.

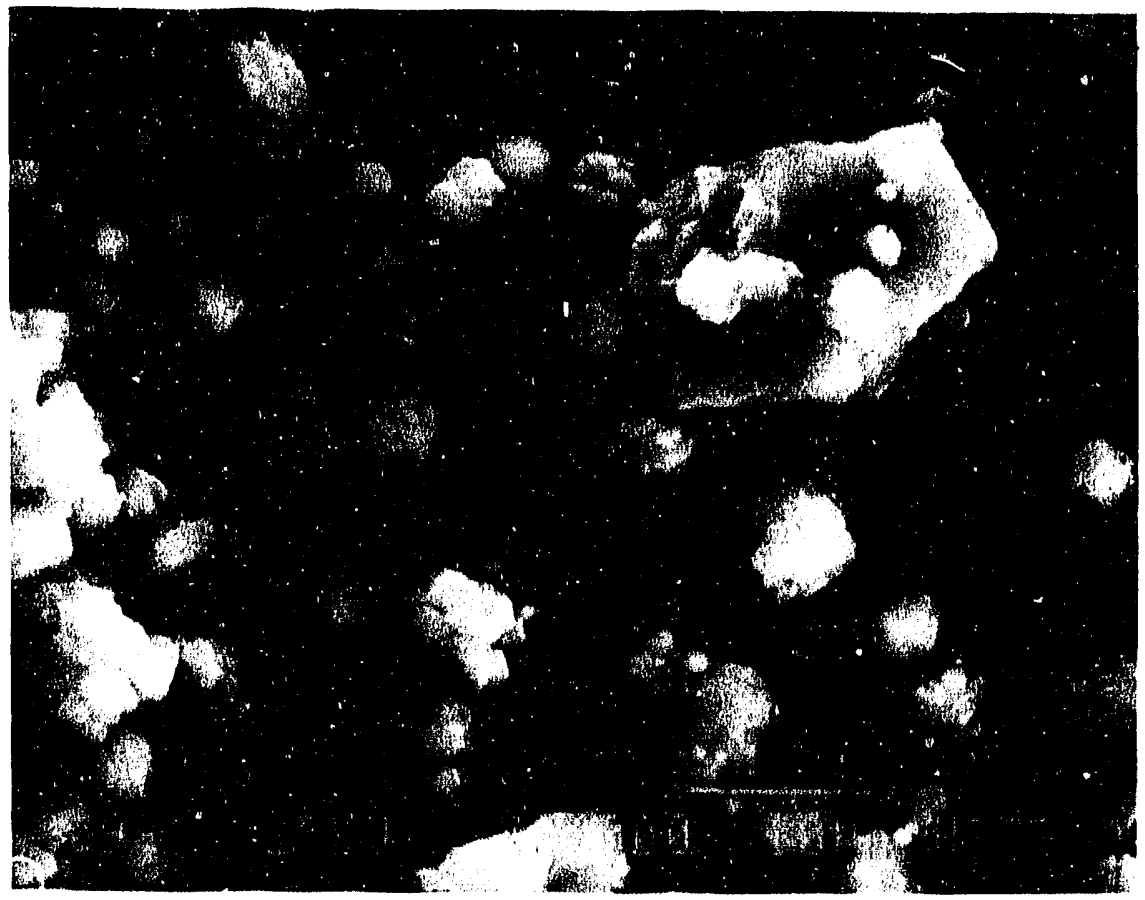

Fig. A8(b). Micrograph of quench particulates at 2000X. 


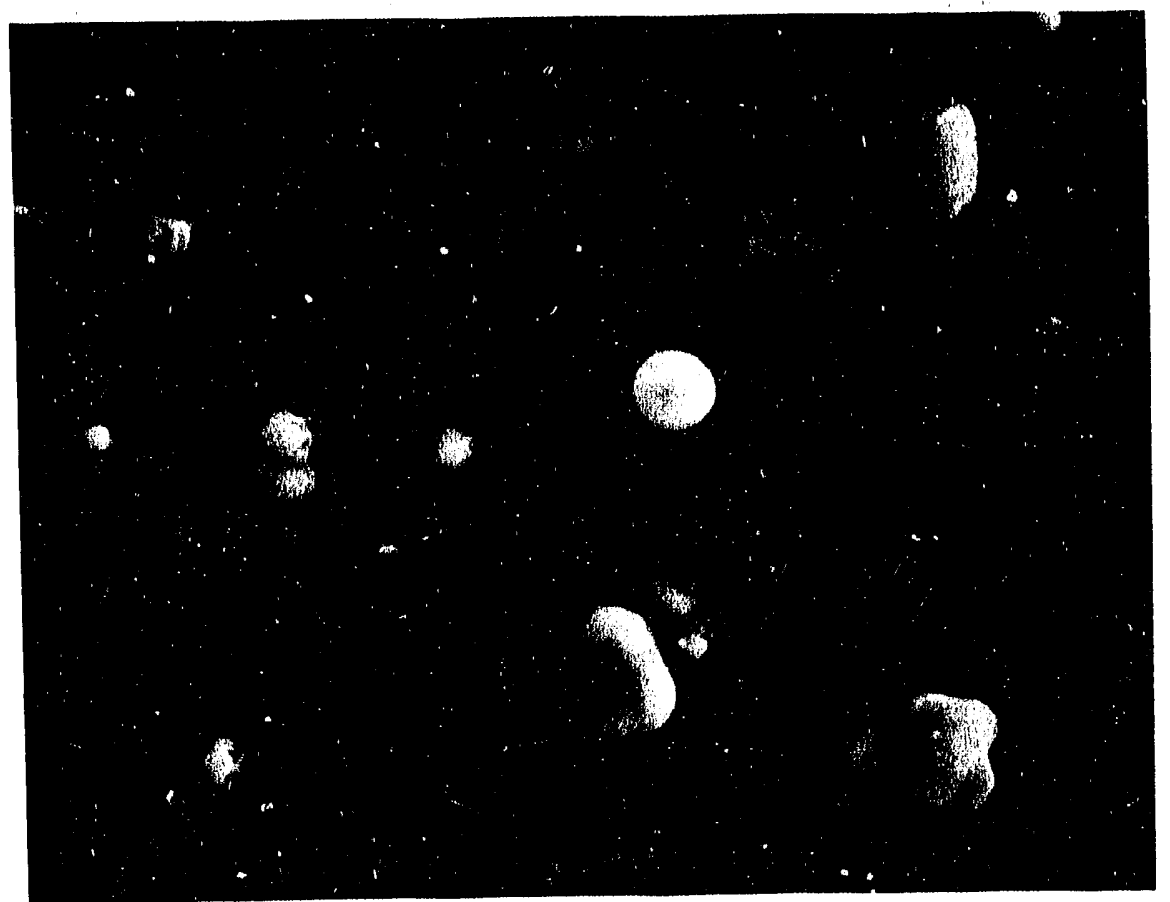

Fig. A.9(a). Micrograph of IWS particulates at 1000X.

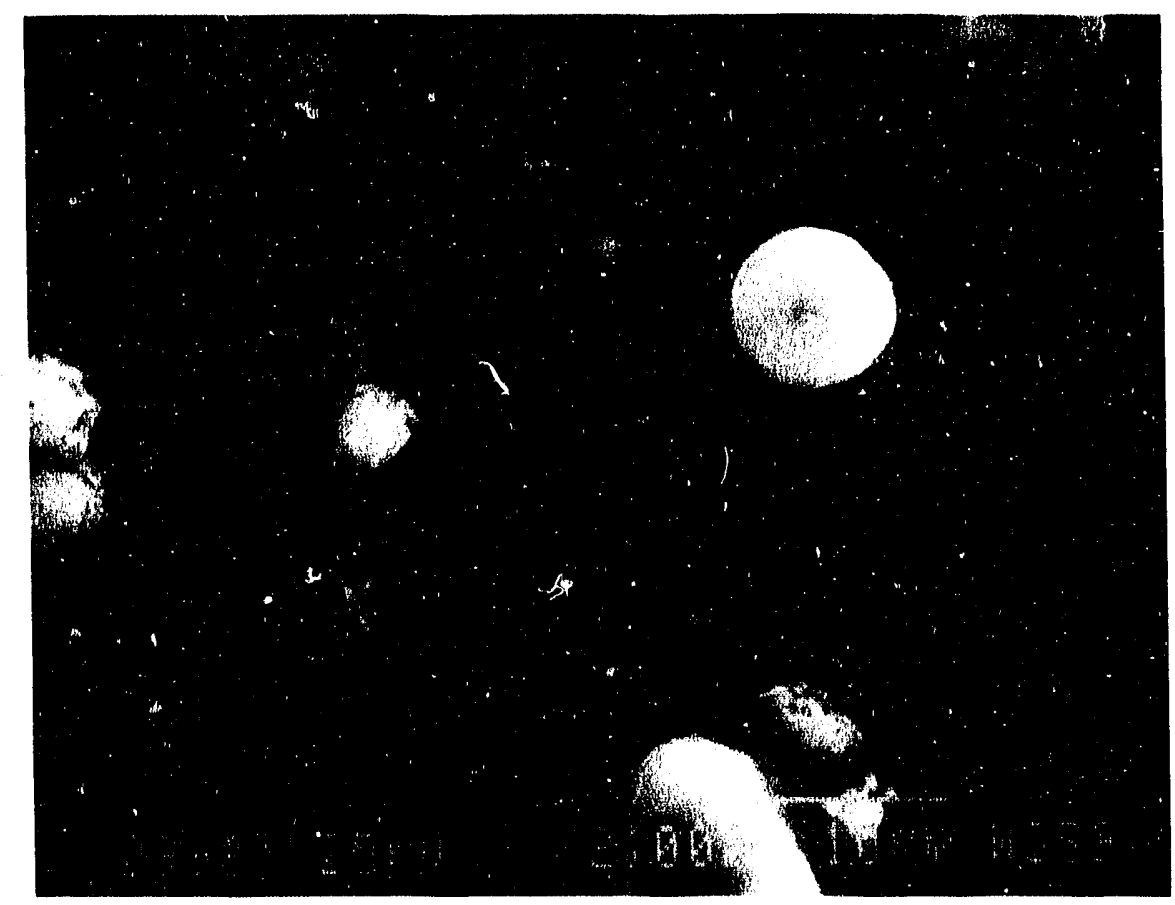

Fig. A.9(b). Micrograph IWS particulates at 2000X. 
Table A.3. EDS results for CNF-filtered material"

\begin{tabular}{lccccc}
\hline Element wt \% & 011991 1AT & $0117912 \mathrm{AT}$ & $0119912 \mathrm{AT}$ & $0117911 \mathrm{AF}$ & $01191 \mathrm{AT}$ \\
\hline Aluminum & 0 & 0 & 0 & 0 & 0 \\
Silicon & 3.5 & 4.3 & 2.9 & 6.4 & 12.5 \\
Phosphorus & 7.6 & 15.2 & 5.8 & 17.8 & 20.0 \\
Sulfur & 1.2 & 7.2 & 1.0 & 8.8 & 2.5 \\
Clorine & 2.1 & 8.7 & 0.5 & 10.2 & 5.4 \\
Calcium & 44.3 & 31.3 & 56.7 & 22.3 & 11.4 \\
Iron & 41.5 & 33.3 & 33.1 & 34.5 & 46.4 \\
\hline
\end{tabular}

${ }^{\circ}$ Units are in weight percent. 


\section{CONCLUSIONS}

Although little correlation could be drawn between the incinerator feed materials and the final purified CNF product, partly because of inconsistencies in the feed material analysis, the CNF-treated waters posed no pollution problems in this instance. Of great importance were the particle size analytical data, which indicate an essential equilibrium distribution between the IWS and the stack particulates, which, if confirmed, could mean inadequate scrubber performance. The EDS elemental analyses of the QBD and the stack particulate are very similar, except for chlorine, which was not washed (intentionally) from the stack sample, suggesting that the same material is present in both. The SEM image analyzer particulate analysis is complementary with the light backscattering technique, providing confidence in both techniques. The extent of agglomeration in the results of the particle size distribution in the stack gases remains an important unknown. 


\section{DISTRIBUTION}

Oak Ridge K-25 Site

E. L. Allred

M. L. Ambrose

R. W. Anderson

W. D. Bostick (5)

T. A. Bowers

J. T. Bradbury, III

D. H. Bunch

H. T. Conner, Jr.

A. C. Coroneos

C. E. Daugherty

J. S. Fickey

C. E. Frye

L. V. Gibson, Jr.

J. H. Gill (Consultant)

R. W. Glass

L. E. Hall

H. M. Henson

W. H. Hermes

D. P. Hoffmann

M. L. Johnson

M. L. Jones

G. J. Kidd, Jr.

C. R. Kirkpatrick

A. C. Lay

K. H. Lee

D. L. Lennon

J. D. Lore

E. W. McDaniel

M. A. McGaha

C. P. McGinnis

W. C. McWhorter

M. E. Mitchell

R. W. Morrow

D. R. Moser

J. E. Powell

A. S. Quist (3)

A. L. Rivera

T. O. Rogers

B. A. Shoemaker

J. L. Shoemaker

J. T. Shor (5)

S. P. N. Singh

H. D. Whitehead, Jr.
Oak Ridge National Laboratory

R. M. Canon

S. E. Gentry

E. S. Harrington

A. P. Malinauskas

F. R. O'Donnell

Paducah Gaseous Diffusion Plant

A. J. Story

Y-12 Plant

R. R. Kimmett

SAIC

T. L. Rucker

U. S. Department of Energy

V. Adams

L. L. Radcliffe

University of California

C. Baker

Westinghouse Savannah River Site

E. Haung

M. S. Hay

H. H. Burns

C. A. Langston

Los Alamos National Laboratory

W. H. McCulla

R. Nakaoka

Lamar University

T. C. Ho

K-25 Site Technical Library 

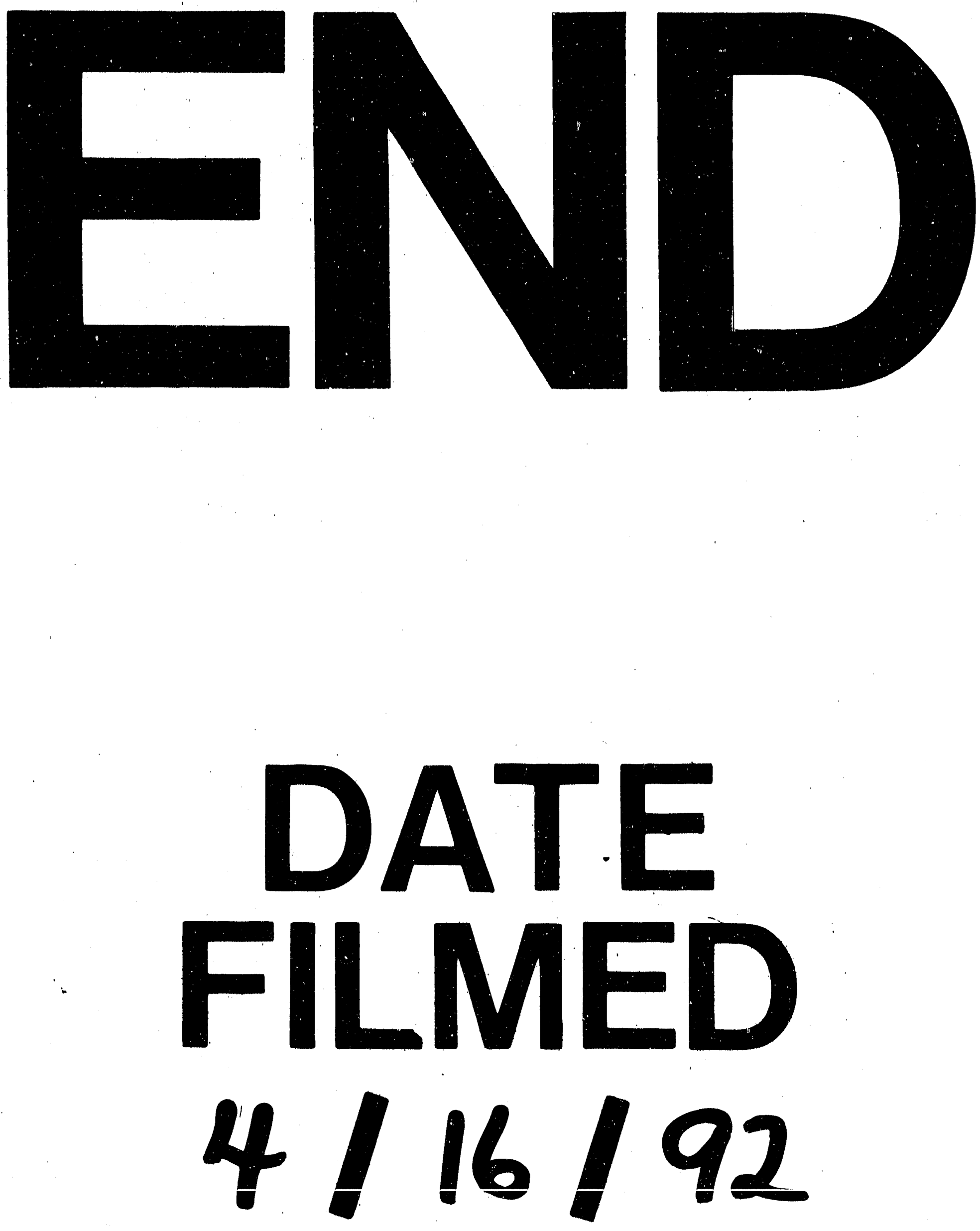
